\title{
An antibody against the $F$ glycoprotein inhibits Nipah and Hendra virus infections
}

\author{
Ha V. Dang, ${ }^{1,6}$, Yee-Peng Chan 2,6, Young-Jun Park1, Joost Snijder ${ }^{1,5}$, Sofia Cheliout Da Silva ${ }^{2}$, \\ Bang Vu ${ }^{2}$, Lianying Yan ${ }^{2}$, Yan-Ru Feng ${ }^{2}$, Barry Rockx ${ }^{3,4}$, Thomas W. Geisbert ${ }^{3}$, Chad E. Mire ${ }^{3}$, \\ Christopher C. Broder ${ }^{2 \star}$ and David Veesler ${ }^{10^{1 \star}}$
}

\begin{abstract}
Nipah virus (NiV) and Hendra virus (HeV) are zoonotic henipaviruses (HNVs) responsible for outbreaks of encephalitis and respiratory illness with fatality rates of $50-100 \%$. No vaccines or licensed therapeutics currently exist to protect humans against NiV or HeV. HNVs enter host cells by fusing the viral and cellular membranes via the concerted action of the attachment (G) and fusion (F) glycoproteins, the main targets of the humoral immune response. Here, we describe the isolation and humanization of a potent monoclonal antibody cross-neutralizing NiV and HeV. Cryo-electron microscopy, triggering and fusion studies show the antibody binds to a prefusion-specific quaternary epitope, conserved in NiV F and HeV F glycoproteins, and prevents membrane fusion and viral entry. This work supports the importance of the HNV prefusion F conformation for eliciting a robust immune response and paves the way for using this antibody for prophylaxis and post-exposure therapy with NiV- and HeV-infected individuals.
\end{abstract}

$\mathrm{N}$ ipah virus $(\mathrm{NiV})$ and Hendra virus $(\mathrm{HeV})$ are related zoonotic paramyxoviruses, belonging to the Henipavirus (HNV) genus. They cause severe encephalitis and respiratory illness, with fatality rates of $50-100 \%$, and are classified as biosafety level 4 (BSL-4) select agents'. Unlike several other paramyxoviruses, HNVs have a broad species tropism (as is the case for canine distemper virus ${ }^{2}$ ) and can infect animals from at least six mammalian orders ${ }^{1}$. Pteropid fruit bats (flying foxes) appear to be the predominant natural reservoir hosts of $\mathrm{HNVs}^{3}$. Since the first outbreaks of $\mathrm{HeV}$ in Australia in 1994 and of $\mathrm{NiV}$ in Malaysia in 1998, HeV repeatedly infected horses in Australia with resultant human exposures ${ }^{4}$, while food-borne mediated $\mathrm{NiV}$ spillovers have occurred nearly every year in Bangladesh ${ }^{5}$. Furthermore, NiV outbreaks have occurred in the Philippines and in India ${ }^{6}$. Besides Asia and Oceania, the detection of anti-HNV antibodies in humans and Pteropus bats in Africa, a continent in which no documented NiV or $\mathrm{HeV}$ outbreaks have occurred, further suggests that future HNV zoonotic emergence is likely to happen ${ }^{7}$. Although more than two billion people live in regions threatened by potential HNV outbreaks, there are no clinically approved vaccines or specific therapeutics against these pathogens.

Paramyxoviruses deliver their genome to the host cytoplasm by fusing their lipid envelope with the cellular membrane to initiate infection. This process requires the concerted action of two surface glycoproteins, attachment $(\mathrm{G} / \mathrm{H} / \mathrm{HN})$ and fusion $(\mathrm{F})$, which sets the paramyxovirus entry machinery apart from all other class I fusion proteins. G is a type II homotetrameric transmembrane protein with an ectodomain comprising a stalk and a C-terminal $\beta$-propeller head, and the latter domain is responsible for binding to ephrinB2 or ephrinB3 (ephrinB2/B3) receptors ${ }^{8-12} . F$ is a homotrimeric type I transmembrane protein that is synthesized as a premature
$\mathrm{F}_{0}$ precursor and cleaved by cathepsin $\mathrm{L}$ during endocytic recycling to yield the mature, disulfide-linked, $F_{1}$ and $F_{2}$ subunits ${ }^{13-15}$. Viral fusion proteins are believed to exist in a kinetically trapped metastable conformation at the virus surface ${ }^{16}$. Upon binding to ephrinB2/B3, NiV G has been proposed to undergo conformational changes leading to $\mathrm{F}$ triggering and insertion of the $\mathrm{F}$ hydrophobic fusion peptide into the target membrane $e^{8,17,18}$. Subsequent refolding into the more stable postfusion $\mathrm{F}$ conformation drives merger of the viral and host membranes to form a pore for genome delivery to the cell cytoplasm, as shown for other paramyxoviruses and pneumoviruses $^{13,19-24}$.

Paramyxovirus $\mathrm{G} / \mathrm{H} / \mathrm{HN}$ and $\mathrm{F}$ glycoproteins are the main targets of the humoral immune response and neutralizing antibodies are the key vaccine-induced protective mechanism against measles virus, for example ${ }^{25}$. Among the few well-characterized anti-HNV G neutralizing monoclonal antibodies (mAbs), m102.4 was previously isolated from a naïve human phage display library and shown to neutralize all known strains of $\mathrm{NiV}$ and $\mathrm{HeV}^{26-28}$. Moreover, m102.4 protected ferrets and African green monkeys from $\mathrm{HeV} / \mathrm{NiV}$ lethal challenges when administered up to several days post infection ${ }^{29-32}$. Anti-F mouse polyclonal antibodies and hybridoma-secreted mAbs were shown to protect hamsters from $\mathrm{NiV}$ and $\mathrm{HeV}$ challenge ${ }^{33-35}$. We further demonstrated that immunization of mice with prefusion $\mathrm{NiV} F$ or $\mathrm{HeV}$ F led to strong homotypic serum neutralization titers, with lower heterotypic titers, whereas postfusion $\mathrm{F}$ failed to elicit a robust neutralizing response ${ }^{17}$. So far, no information is available about the epitopes recognized by HNV F mAbs and their potential for use as therapeutics in humans or to guide reverse vaccinology initiatives.

We previously isolated a hybridoma secreting a murine $\mathrm{mAb}$ that recognizes prefusion $\mathrm{NiV} \mathrm{F}$ and $\mathrm{HeV} F$ glycoproteins, which

'Department of Biochemistry, University of Washington, Seattle, WA, USA. ${ }^{2}$ Department of Microbiology and Immunology, Uniformed Services University, Bethesda, MD, USA. ${ }^{3}$ Sealy Center for Vaccine Development, Departments of Pathology and Microbiology \& Immunology, The University of Texas Medical Branch, Galveston, TX, USA. ${ }^{4}$ Department of Viroscience, Erasmus University Medical Center, Rotterdam, The Netherlands. ${ }^{5}$ Present address: Biomolecular Mass Spectrometry and Proteomics, Bijvoet Center for Biomolecular Research, Utrecht University, Utrecht, The Netherlands. ${ }^{6}$ These authors contributed equally: Ha V. Dang, Yee-Peng Chan. *e-mail: christopher.broder@usuhs.edu; dveesler@uw.edu 
we designated $5 \mathrm{~B} 3^{17}$. We report here the cloning, sequencing and humanization of 5B3 (h5B3.1) and demonstrate it bound with high affinity to prefusion $\mathrm{NiV} F$ and $\mathrm{HeV}$ F. Neutralization assays, carried out under BSL-4 containment, showed that $5 \mathrm{~B} 3$ and h5B3.1 potently inhibited $\mathrm{NiV}$ and $\mathrm{HeV}$ infection of target cells. We determined a cryo-electron microscopy (cryo-EM) structure of the NiV F trimer in complex with 5B3 and found the antibody binds to a prefusionspecific quaternary epitope that is conserved in $\mathrm{NiV} \mathrm{F}$ and $\mathrm{HeV} F$. Our structural data, combined with F-triggering and membrane fusion assays, demonstrate that $5 \mathrm{~B} 3$ locks $\mathrm{F}$ in the prefusion conformation and prevents membrane fusion via molecular stapling, providing a molecular rationale for its potency. These results define a critical neutralization epitope on the surface of the $\mathrm{NiV}$ and $\mathrm{HeV} \mathrm{F}$ glycoproteins and pave the way for the future use of h5B3.1 for prophylaxis or as therapeutic for $\mathrm{NiV}$ - and $\mathrm{HeV}$-infected individuals.

\section{Results}

$5 \mathrm{~B} 3$ and h5B3.1 antibodies potently neutralize $\mathrm{NiV}$ and $\mathrm{HeV}$. To understand the humoral immune response directed at the HNV F glycoprotein, we cloned and sequenced the $5 \mathrm{~B} 3$ neutralizing $\mathrm{mAb}$ from hybridomas previously obtained upon mice immunization with a prefusion NiV F ectodomain trimer ${ }^{17}$. The resulting antibody was subsequently humanized (and designated h5B3.1) to enable future therapeutic use in humans. We used biolayer interferometry to characterize the binding kinetics and affinity of the 5B3 and h5B3.1 Fab fragments to prefusion NiV F and HeV F ectodomain trimers immobilized on the surface of biosensors. The 5B3 Fab bound to $\mathrm{HeV} \mathrm{F/NiV} \mathrm{F} \mathrm{with} \mathrm{equilibrium} \mathrm{dissociation} \mathrm{constants}$ of $4.6-10 \mathrm{nM}$, compared to equilibrium dissociation constants of 31-61 nM for interactions with the h5B3.1 Fab (Fig. 1a-d and Supplementary Table 1). Analysis of the determined association and dissociation rate constants indicate that the weaker binding affinity of h5B3.1, compared to 5B3, largely resulted from an enhanced dissociation rate of h5B3.1 (Supplementary Table 1).

Subsequent neutralization assays were carried out using authentic NiV-Malaysia (NiV-M), NiV-Bangladesh (NiV-B) and $\mathrm{HeV}$ virions under BSL-4 containment. Plaque reduction assays were performed to analyze the neutralization of viruses pre-incubated with varying amounts of 5B3 or h5B3.1 antibodies. We determined mean half-maximal inhibitory concentrations of $1.2 \mu \mathrm{g} \mathrm{ml}^{-1}$ (5B3) and $0.9 \mu \mathrm{g} \mathrm{ml}^{-1}$ (h5B3.1) for NiV-M, $1.3 \mu \mathrm{g} \mathrm{ml}^{-1}$ (5B3) and $0.6 \mu \mathrm{g} \mathrm{ml}^{-1}$ (h5B3.1) for NiV-B and $1.4 \mu \mathrm{g} \mathrm{ml}^{-1}$ (5B3) and $1.3 \mu \mathrm{g} \mathrm{ml}^{-1}$ (h5B3.1) for $\mathrm{HeV}$ (Fig. 1e-g). These results show both 5B3 and h5B3.1 potently inhibited infectious $\mathrm{NiV}$ and $\mathrm{HeV}$, the two $\mathrm{HNV}$ s responsible for recurrent outbreaks of lethal encephalitis and respiratory diseases in humans.

Cryo-electron microscopy structure of $5 \mathrm{~B} 3$ in complex with the NiV F glycoprotein. To elucidate the mechanism of 5B3-mediated neutralization of $\mathrm{NiV}$ and $\mathrm{HeV}$, we determined a cryo-EM structure of a stabilized NiV F ectodomain trimer in complex with the 5B3 antibody Fab fragment at $3.5 \AA$ resolution (Fig. 2a,b, Table 1 and Extended Data 1). To assist model building, we also crystallized the isolated 5B3 Fab fragment and determined its structure at $1.5 \AA$ resolution using X-ray crystallography (Table 2). In agreement with the features observed in the cryo-EM map, the local resolution is highest for most of the NiV F and the 5B3 variable domains, including the interface between NiV F and 5B3, whereas the Fab constant domains are poorly resolved, due to elbow flexibility between constant and variable domains, and were not modeled. The final model includes NiV F residues $27-480$ with a chain break between residues 105 and 112 . 5B3 binds to a quaternary epitope on domain III of the NiV F globular head, with a stoichiometry of three Fabs bound to an F trimer (Fig. 2a,b, Table 1 and Extended Data 1 and 2).

The cryo-EM map resolves the four N-linked oligosaccharides present on each NiV F protomer (at positions Asn67, Asn99,
Asn414 and Asn464) and reveals 5B3 recognizes a glycan-free epitope on the F surface. We could not detect an oligosaccharide at position Asn64 in the cryo-EM reconstruction (Fig. 2a,b), in agreement with previous biochemical studies ${ }^{36-38}$. All six complementarity-determining regions (CDRs) (and the light chain framework region 2) contribute to the paratope and bury $980 \AA^{2}$ at the interface with the NiV F epitope, which mostly resides within one protomer (Fig. 3a,b). CDRL1 contacts the NiV F heptad-repeat A (HRA) $\beta$-hairpin via electrostatic interactions between $\mathrm{Gln} 27_{5 \mathrm{~B} 3}$ and

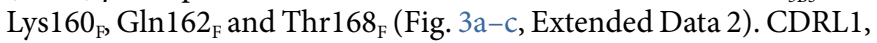
CDRL 3 and CDRH 3 bind to the core $\beta$-sheet in domain III via contacts with both F2 (residues 53-55) and F1 (residues 282-285) subunits (Fig. $3 \mathrm{a}-\mathrm{c}$ ). CDRH2 protrudes at the interface between two $\mathrm{NiV}$ F protomers and interacts with a segment $\mathrm{C}$-terminal to the central helix and with the upstream helix of a neighboring protomer (Fig. 3a-c and Extended Data 2). Comparison with the unliganded $\mathrm{NiV} F$ structure reveals that $5 \mathrm{~B} 3$ binding induces a local reorganization (or stabilizes a different conformation) of the HRA $\beta$-hairpin (residues 160-170) and of residues 248-252 (Extended Data 3).

$5 \mathrm{~B} 3$ relies on an atypical binding mode to NiV F with nearly equal contributions of the heavy (48\%) and light (52\%) chains to the antibody buried surface area. This, in part, results from the fact that CDRL1 is making a greater contribution to the paratope than the nine residue-long CDRH3 (268 $\AA^{2}$ versus $190 \AA^{2}$ of buried surface area, respectively), in contrast with the canonical CDRH3-dominated antibody/antigen interfaces. To confirm these findings, we probed the NiV F binding ability of single-chain $(\mathrm{scFv})$ chimeric constructs in which either the variable heavy (VH) or variable light (VL) h5B3 chains were replaced with an unrelated chain from a human $\mathrm{scFv}$ library. Although h5B3 scFv immunoprecipitated full-length NiV F, none of the $\mathrm{scFv}$ chimeras did, in agreement with the equivalent contributions to binding of the heavy and light chains observed in our structure (Fig. 3a,b and Extended Data 4a). The structural data were further validated using site-directed mutagenesis of selected residues participating in the NiV F epitope followed by 5B3-mediated immunoprecipitation to assess residual binding (Extended Data $4 \mathrm{~b}$ ). We also used the prefusion F specific 12B2 antibody as well as a cell-cell fusion assay to probe the conformational integrity of the F mutants analyzed (Extended Data 4b,c). The NiV F K55A substitution inhibited $5 \mathrm{~B} 3$ recognition, which is probably explained by the loss of interactions with CDRL1 Trp32 $2_{5 \mathrm{~B} 3}$ and CDRL3 Tyr92 ${ }_{5 \mathrm{~B} 3}$ residues, as visualized in our structure. Furthermore, abrogation of 5B3 binding to NiV F L53D or L53S probably resulted from reduction of favorable interactions with CDRL1 Trp32 $2_{5 \mathrm{~B} 3}$, CDRL3 Phe91 $1_{5 \mathrm{~B} 3}$ and CRH3 Tyr $102_{5 \mathrm{~B} 3}$. Given that the tested mutants bound to the12B2 antibody and retained $40-100 \%$ of the wild-type F fusion activity (Extended Data $4 \mathrm{~b}, \mathrm{c}$ ), we conclude that the observed loss of binding largely resulted from specific disruption of interactions with 5B3, without major effects on the overall F structure.

Analysis of the structure rationalizes the observed cross-neutralization of $\mathrm{NiV}$ and $\mathrm{HeV}$ because 35 out of the $39 \mathrm{NiV} F$ residues buried upon $5 \mathrm{~B} 3$ binding are strictly conserved. Variable positions

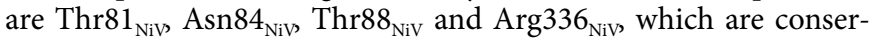
vatively or semi-conservatively substituted to $S e r 81_{\mathrm{HeV}}$, Thr $84_{\mathrm{HeV}}$, Ser88 $8_{\mathrm{HeV}}$ and Lys336 $6_{\mathrm{HeV}}$, respectively (Fig. 3d).

Isolation of a $\mathrm{NiV}$ neutralization-escape mutant. As for other RNA viruses, the high mutation rate of HNVs could yield variants able to overcome 5B3 inhibition. For example, we showed that passaging $\mathrm{NiV}$ or $\mathrm{HeV}$ with anti-HNV G antibodies led to the isolation of viral mutants escaping neutralization by the respective antibody ${ }^{28,39}$. To assess the possibility of generating 5B3 neutralization-escape virus mutants, such as the aforementioned bindingdeficient $\mathrm{F}$ mutants identified by site-directed mutagenesis, we passaged authentic NiV for three rounds in the presence of 5B3 in BSL- 4 containment. Plaque purified resistant viruses were isolated, 


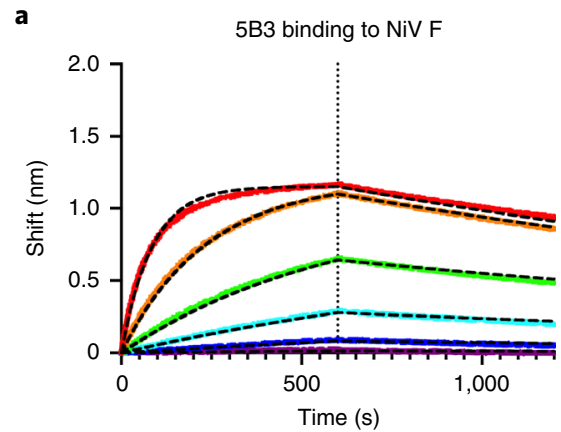

c
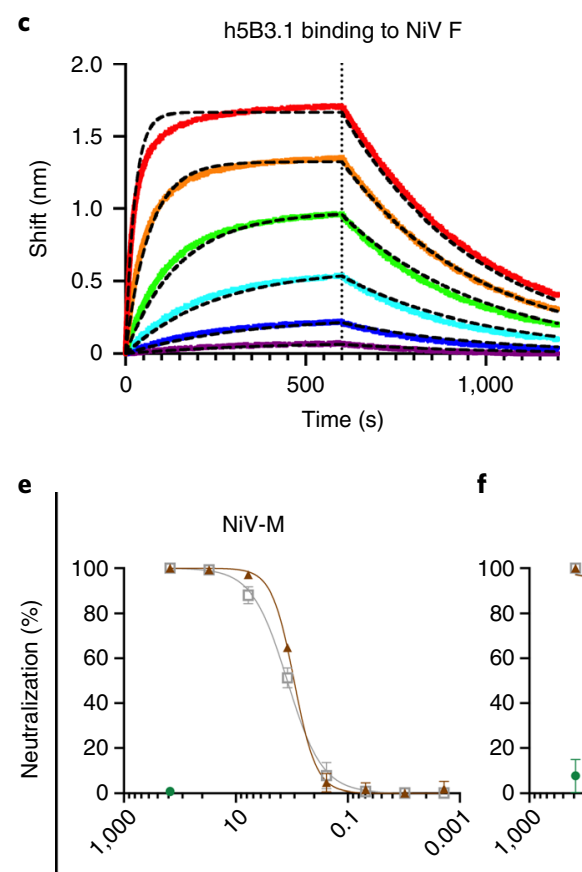

f
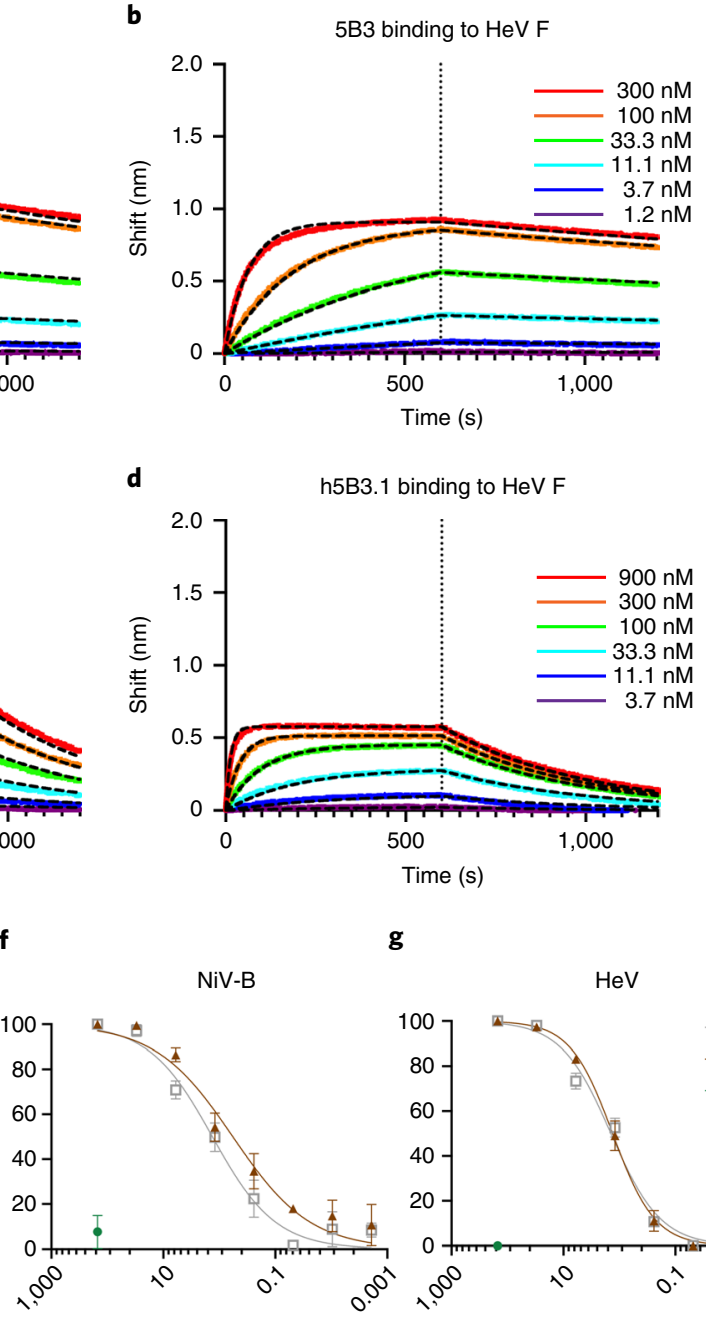

d

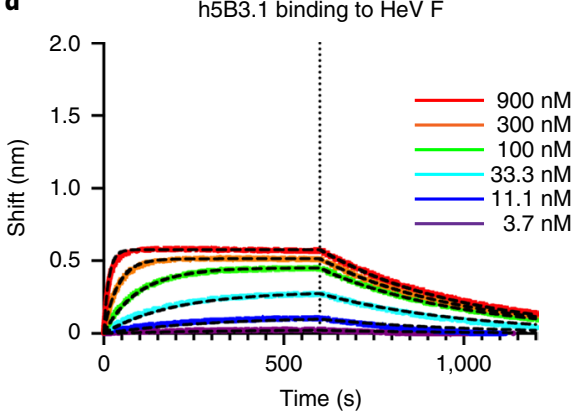

$\mathbf{g}$

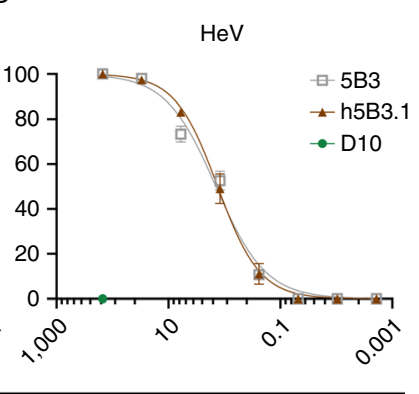

mAb concentration $\left(\mu \mathrm{g} \mathrm{ml}^{-1}\right)$

Fig. 1 | The 5B3 and h5B3.1 antibodies cross-react with NiV F and HeV F and potently neutralize NiV and HeV. a-d, Binding of 5B3 (a,b) or h5B3.1 (c,d) Fab fragments to immobilized NiV F (a,c) or $\mathrm{HeV} \mathrm{F} \mathrm{(b,d)} \mathrm{analyzed} \mathrm{by} \mathrm{biolayer} \mathrm{interferometry.} \mathrm{The} \mathrm{concentrations} \mathrm{of} \mathrm{injected} \mathrm{5B3} \mathrm{and} \mathrm{h5B3.1} \mathrm{are} \mathrm{indicated}$ in $\mathbf{b}$ and $\mathbf{d}$, respectively. Fitted curves are shown as black dashed lines. The vertical dotted lines correspond to the transition between the association and dissociation phases. The experiments were performed in replicates with two different preparations of NiV F and of HeV F and a representative experiment is shown. e-g, Neutralization of authentic NiV-Malaysia (NiV-M) (e), NiV-Bangladesh (NiV-B) (f) and HeV (g) by the 5B3 (grey) and h5B3.1 (brown) immunoglobulin-Gs (IgGs). D10 (green) is an anti-HIV antibody used as negative control. Data shown are mean and s.d. for $n=3$ independent experiments (with independent virus preparations).

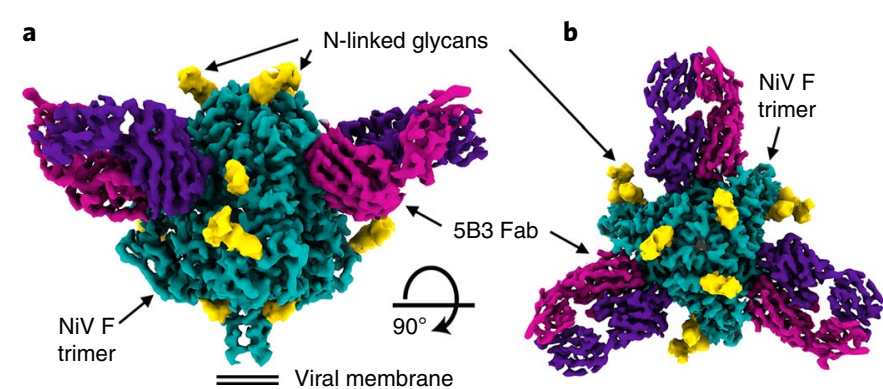

Fig. 2 | Cryo-EM structure of NiV F in complex with the 5B3 neutralizing antibody. a,b, Two orthogonal views of the cryo-EM map at $3.5 \AA$ resolution from the side (a) and from the top (b), facing toward the viral membrane. NiV F ectodomain trimer, teal; NiV F glycans, gold; 5B3 Fab heavy chain, purple; 5B3 Fab light chain, pink. The glycans are rendered using the unsharpened reconstruction. and viral RNA from five NiV isolates was reverse-transcribed into cDNA for sequencing of the $\mathrm{F}$ gene. All five NiV escape mutants harbored the same F K55E substitution. This finding supports our aforementioned mutagenesis data because the NiV F K55A was completely defective in $5 \mathrm{~B} 3$ binding. We recombinantly produced the K55E F mutant and observed it could not bind 5B3 while maintaining its ability to interact with $12 \mathrm{~B} 2$ and to promote wild-type cell-cell fusion activity (Extended Data $4 b, c)$. These experiments are in full agreement with our structural and biochemical data and show that NiV could escape 5B3 neutralization without affecting F-mediated fusion, although the impact of the identified substitution on viral growth is not known.

The $5 \mathrm{~B} 3$ antibody inhibits F-mediated fusion. Our structural data suggest $5 \mathrm{~B} 3$ prevents fusogenic conformational changes leading to membrane fusion by locking NiV F in the prefusion state. The antibody recognizes a discontinuous epitope, spanning two neighboring protomers, present only in prefusion $\mathrm{F}$, based on the conformational 


\begin{tabular}{|c|c|}
\hline & $\begin{array}{l}\text { NiV F-5B3 (EMD-20584, } \\
\text { PDB 6TYS) }\end{array}$ \\
\hline \multicolumn{2}{|l|}{ Data collection and processing } \\
\hline Magnification & 105,000 \\
\hline Voltage (kV) & 300 \\
\hline Electron exposure $\left(\mathrm{e}^{-} \AA^{-2}\right)$ & 40 \\
\hline Defocus range $(\mu \mathrm{m})$ & $1.0-3.2$ \\
\hline Pixel size $(\AA)$ & 1.37 \\
\hline Symmetry imposed & $\mathrm{C} 3$ \\
\hline Initial particle images (no.) & 380,459 \\
\hline Final particle images (no.) & 38,756 \\
\hline Map resolution $(\AA)$ & 3.5 \\
\hline FSC threshold & 0.143 \\
\hline \multicolumn{2}{|l|}{ Refinement } \\
\hline Model resolution $(\AA)$ & 3.5 \\
\hline FSC threshold & 0.5 \\
\hline Map sharpening $B$ factor $\left(\AA^{2}\right)$ & -103 \\
\hline \multicolumn{2}{|l|}{ Model composition } \\
\hline Protein residues & 2,025 \\
\hline \multicolumn{2}{|l|}{$B$ factors $\left(\AA^{2}\right)$} \\
\hline Protein & 38.9 \\
\hline \multicolumn{2}{|l|}{ R.m.s. deviations } \\
\hline Bond lengths $(\AA)$ & 0.02 \\
\hline Bond angles $\left({ }^{\circ}\right)$ & 1.9 \\
\hline \multicolumn{2}{|l|}{ Validation } \\
\hline MolProbity score & 0.71 \\
\hline Clashscore & 0.65 \\
\hline Poor rotamers (\%) & 0.17 \\
\hline \multicolumn{2}{|l|}{ Ramachandran plot } \\
\hline Favored (\%) & 98.05 \\
\hline Allowed (\%) & 100 \\
\hline EMRinger score & 2.59 \\
\hline
\end{tabular}

changes observed in the related parainfluenza virus 3 postfusion $\mathrm{F}$ and respiratory syncytial virus postfusion $\mathrm{F}$ structures ${ }^{20,23,24}$ (Figs. $3 a-c$ and $4 a, b)$. Furthermore, CDRL1 interactions with the HRA $\beta$-hairpin hinders refolding of the latter motif to contribute to the formation of an elongated central helix, observed in the postfusion $\mathrm{F}$ state. This antibody-mediated molecular stapling strategy, involving simultaneous interactions with protein segments that are close to each other in prefusion $\mathrm{F}$ but far apart in postfusion $\mathrm{F}$ (Fig. 4a,b), is conceptually equivalent to the disulfide stapling approach implemented for stabilizing the prefusion conformation of measles virus $\mathrm{F}^{40}$, respiratory syncytial virus (RSV) $\mathrm{F}^{41}, \mathrm{HeV} \mathrm{F}^{42}$ and PIV $\mathrm{F}^{43}$ glycoproteins. Finally, we predict unfavorable steric clashes would occur with a 5B3 antibody bound to a neighboring protomer upon F refolding.

To validate the hypothesis that $5 \mathrm{~B} 3$ locks NiV F in the prefusion conformation, we used an in vitro $\mathrm{F}$ triggering assay entailing (1) cleavage of the wild-type $\mathrm{NiV} \mathrm{F}_{0}$ ectodomain trimer with trypsin, under limited proteolysis conditions, to recapitulate the in vivo cathepsin L-mediated production of $\mathrm{F}_{1}$ and $\mathrm{F}_{2}{ }^{14,15}$ and (2) incubation at $50^{\circ} \mathrm{C}$ to promote refolding of the trypsin-cleaved prefusion $\mathrm{F}$ trimer to the postfusion conformation ${ }^{17,19}$. We previously showed peptides derived from the heptad-repeat $\mathrm{B}(\mathrm{HRB})$ sequence of $\mathrm{NiV}$
Table 2 | X-ray crystallography data collection and refinement statistics

$5 B 3 \mathrm{Fab}($ PDB 6U1T)

\begin{tabular}{|ll}
\hline Data collection & $C 222_{1}$ \\
\hline Space group & \\
\hline Cell dimensions & $78.12,95.01,137.20$ \\
\hline$a, b, c(\AA)$ & $90,90,90$ \\
$\alpha, \beta, \gamma\left(^{\circ}\right)$ & $68.6-1.48(1.56-1.48)^{a}$ \\
\hline Resolution $(\AA)$ & $8.0(90.4)$ \\
\hline$R_{\text {sym }}(\%)$ & $10.2(1.3)$ \\
\hline$/ / \sigma(I)$ & $0.998(0.472)$ \\
\hline$C C_{1 / 2}$ & $99.7(97.8)$ \\
\hline Completeness $(\%)$ & $5.6(3.6)$ \\
\hline Redundancy & \\
\hline Refinement & $68.6-1.48$ \\
\hline Resolution $(\AA)$ & 79,965 \\
\hline No. of reflections & $13.7 / 17.3$ \\
\hline$R_{\text {work }} / R_{\text {free }}$ & \\
\hline No. of atoms & 3,577 \\
\hline Protein & 1 \\
\hline Cl- ion & 557 \\
\hline Water & \\
\hline$B$ factors & 21.1 \\
\hline Protein & 37.9 \\
\hline Other atoms & \\
\hline B.m.s. deviations & 0.01 \\
\hline Bond lengths $(\AA)$ & 1.42 \\
\hline$A$ singles $\left({ }^{\circ}\right)$ & \\
\hline
\end{tabular}

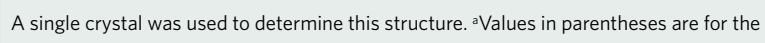
highest-resolution shell.

F or $\mathrm{HeV} F$ prevent completion of $\mathrm{F}$ refolding and are potent inhibitors of fusion and live virus infection ${ }^{44,45}$. Furthermore, when the triggering assay was carried out in the presence of a biotinylated HRB peptide, a conformational intermediate of the fusion reaction was captured and could be used as a reporter of $\mathrm{F}$ activation. Using this approach, we demonstrate here that addition of 5B3 or h5B3.1 during the triggering assay blocked fusogenic conformational changes in a concentration-dependent manner, whereas a nonneutralizing control antibody (13G5), specific for postfusion $\mathrm{F}$, did not (Fig. 4c,d). Subsequent antibody affinity purification (protein $\mathrm{G}$ ) of the material not captured by the HRB peptide showed 5B3 (or h5B3.1) remained bound to F (Fig. 4d), supporting the hypothesis that 5B3/h5B3.1 trap NiV F in the prefusion conformation. Finally, capture of an $\mathrm{F}$ intermediate could be partially rescued by raising the temperature to $\geq 60^{\circ} \mathrm{C}$, indicating that binding of $5 \mathrm{~B} 3 / \mathrm{h} 5 \mathrm{~B} 3.1$ stabilizes NiV F by raising the energy barrier for transitioning to the postfusion state (Fig. 4e). In summary, the structural and biochemical data presented here show 5B3/h5B3.1 inhibited fusogenic conformational changes by locking $\mathrm{F}$ in the prefusion state and raising the free energy of activation for fusion triggering.

To further study the mechanism of action of 5B3/h5B3.1 in the context of a full-length, membrane-embedded $\mathrm{F}$ glycoprotein, we carried out cell-cell fusion assays in the presence of varying concentrations of mAbs. We observed that 5B3 and h5B3.1 prevented $\mathrm{NiV}$ F- and $\mathrm{HeV}$ F-mediated membrane fusion in a concentration-dependent manner, consistent with the expectation 
a
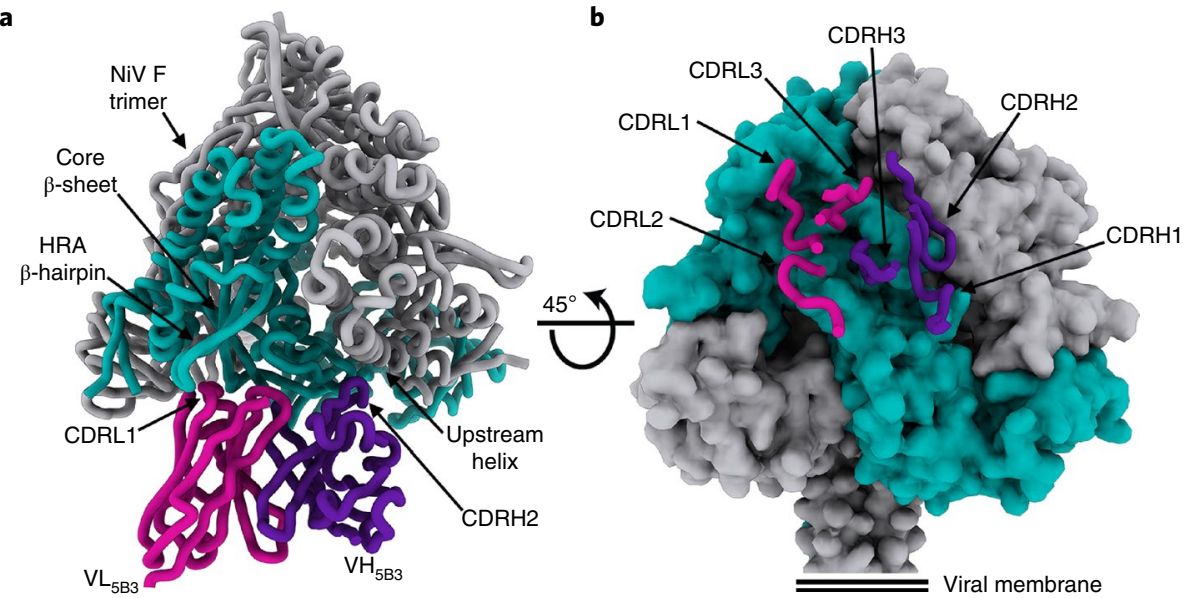
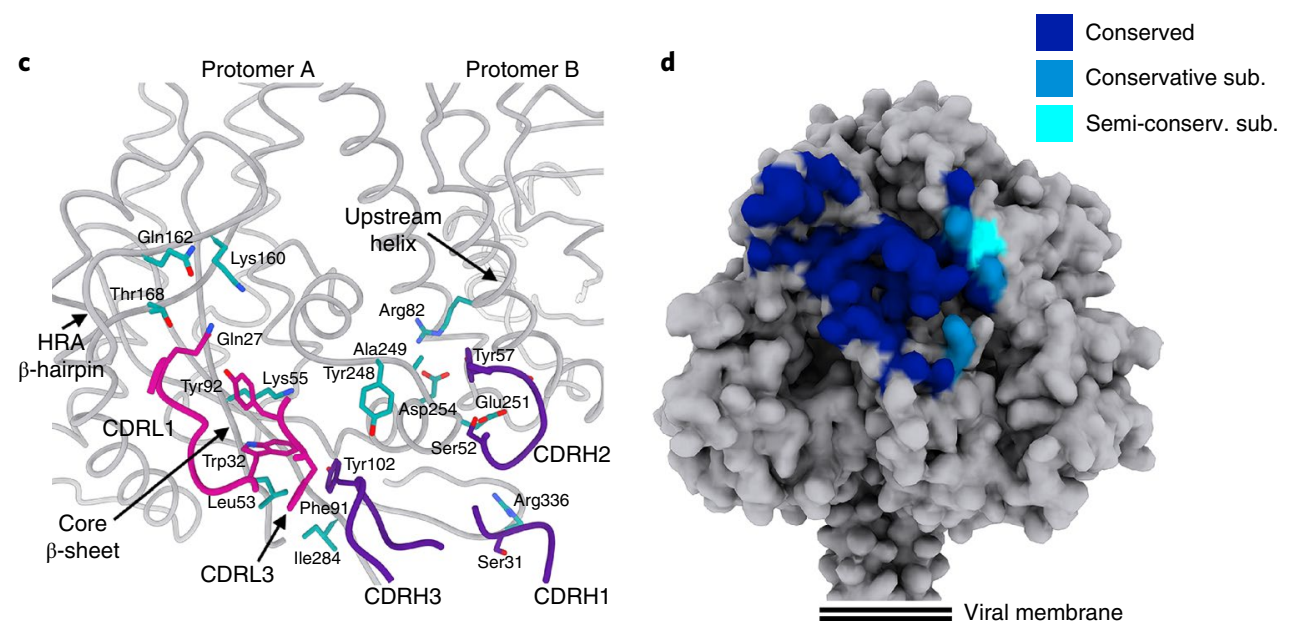

Fig. 3 | The 5B3 neutralizing antibody recognizes a conserved quaternary epitope on the NiV F glycoprotein. a, Ribbon diagram of the NiV F trimer in complex with the 5B3 Fab fragment. One F protomer is rendered in teal and the other two protomers in grey. Only one Fab fragment is shown for clarity. b, Molecular surface representation of the NiV F trimer with the 5B3 CDR loops shown as ribbons, highlighting the quaternary nature of the epitope. c, Enlarged view of the interface between NiV F and 5B3 with selected residues rendered as sticks. NiV F residues are colored teal with oxygen and nitrogen atoms colored red and blue, respectively. In a-c, the $5 B 3$ variable heavy $\left(\mathrm{VH}_{5 B 3}\right)$ and light $\left(\mathrm{VL}_{5 B 3}\right)$ chains are colored purple and pink, respectively. d, Molecular surface representation of the NiV F trimer showing the 5B3 footprint colored by residue conservation among NiV F and HeV F glycoproteins. Conservative sub.: conservative substitution; semi-conserv. sub.: semi-conservative substitution.

that trapping $\mathrm{F}$ in the prefusion conformation actually resulted in inhibition of membrane fusion (Figs. 4f,g and 5).

\section{Discussion}

The paramyxovirus and pneumovirus F glycoproteins are key players of viral entry, promoting fusion of the viral and host membranes through large-scale structural rearrangements ${ }^{13,20-24}$. The F conformation presented to the immune system can be a major determinant of the antibody response elicited by these glycoproteins. Previous work showed that most of the RSV-neutralizing activity in human serum is conferred by antibodies specifically recognizing prefusion $\mathrm{F}^{46}$. Structure-based physical stabilization of the RSV F prefusion state via mutations and fusion to another protein (domain) as well as multivalent display on a computationally designed nanoparticle platform correlated with increased elicitation of neutralizing $\mathrm{mAbs}^{22,41,47,48}$. Prefusion stabilized $\mathrm{F}$ also induced greater neutralizing humoral immune responses than postfusion $\mathrm{F}$ against parainfluenza viruses in mice and rhesus macaques ${ }^{43}$. However, antibodies present in the sera of mice immunized with human metapneumovirus prefusion or postfusion $\mathrm{F}$ ectodomain trimers bound similarly to either protein conformation and equally neutralized virus infectivity, demonstrating that prefusion and postfusion $\mathrm{F}$ share most neutralizing epitopes for this virus ${ }^{49}$. We previously established that fusing a GCN4 trimeric motif at the $\mathrm{C}$-terminal end of the $\mathrm{NiV} \mathrm{F}$ and $\mathrm{HeV} \mathrm{F}$ ectodomains resulted in the production of prefusion stabilized trimers that could elicit a neutralizing antibody response in mice ${ }^{17}$. No HNV F mAb, however, had been characterized at the molecular level.

Here, we have sequenced and humanized the 5B3 neutralizing $\mathrm{mAb}$ and demonstrated its ability to cross-neutralize authentic NiV and $\mathrm{HeV}$. We show 5B3 and h5B3.1 inhibited membrane fusion by locking $\mathrm{F}$ in the prefusion conformation upon binding to a conformational (quaternary) epitope, which is reorganized during the fusion reaction. This mechanism of action rationalizes the potent 5B3/h5B3.1-mediated neutralization of $\mathrm{NiV}$ and $\mathrm{HeV}$ entry into target cells and is reminiscent of D25 inhibition of RSV via binding to and stabilization of prefusion $\mathrm{F}^{22}$. These findings are also in line with the enhanced properties of RSV and parainfluenza virus prefusion-stabilized $\mathrm{F}$ glycoproteins as candidate vaccine immunogens compared to the corresponding postfusion $\mathrm{F}^{41,43,48}$. Accordingly, the previously developed disulfide-stabilized prefusion $\mathrm{HeV} \mathrm{F}^{42}$, and the corresponding prefusion NiV F construct engineered here, bear the promise of eliciting stronger neutralizing antibody titers than GCN4-only stabilized F glycoprotein ectodomains, by preventing refolding to the postfusion conformation. 


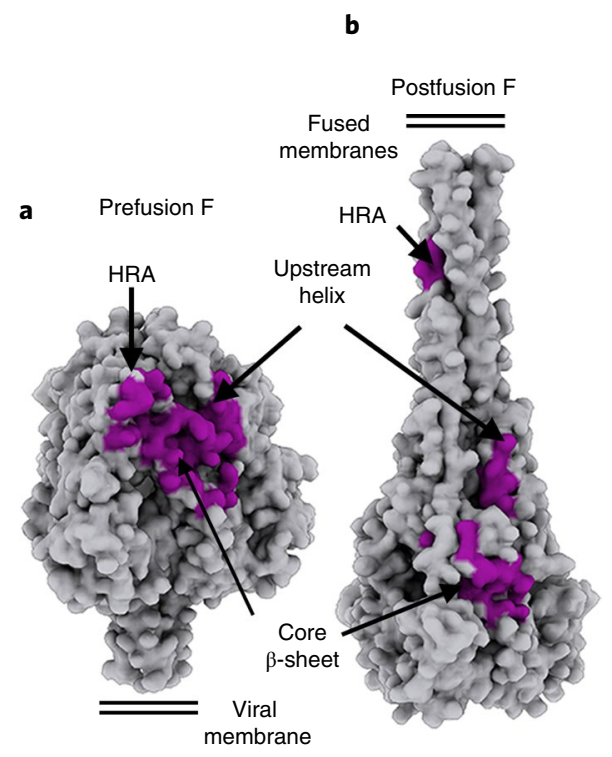

c

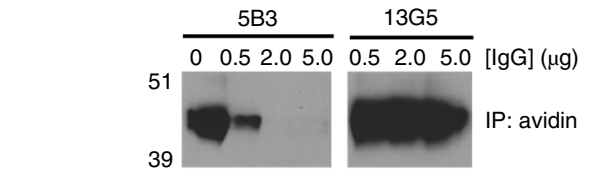

d
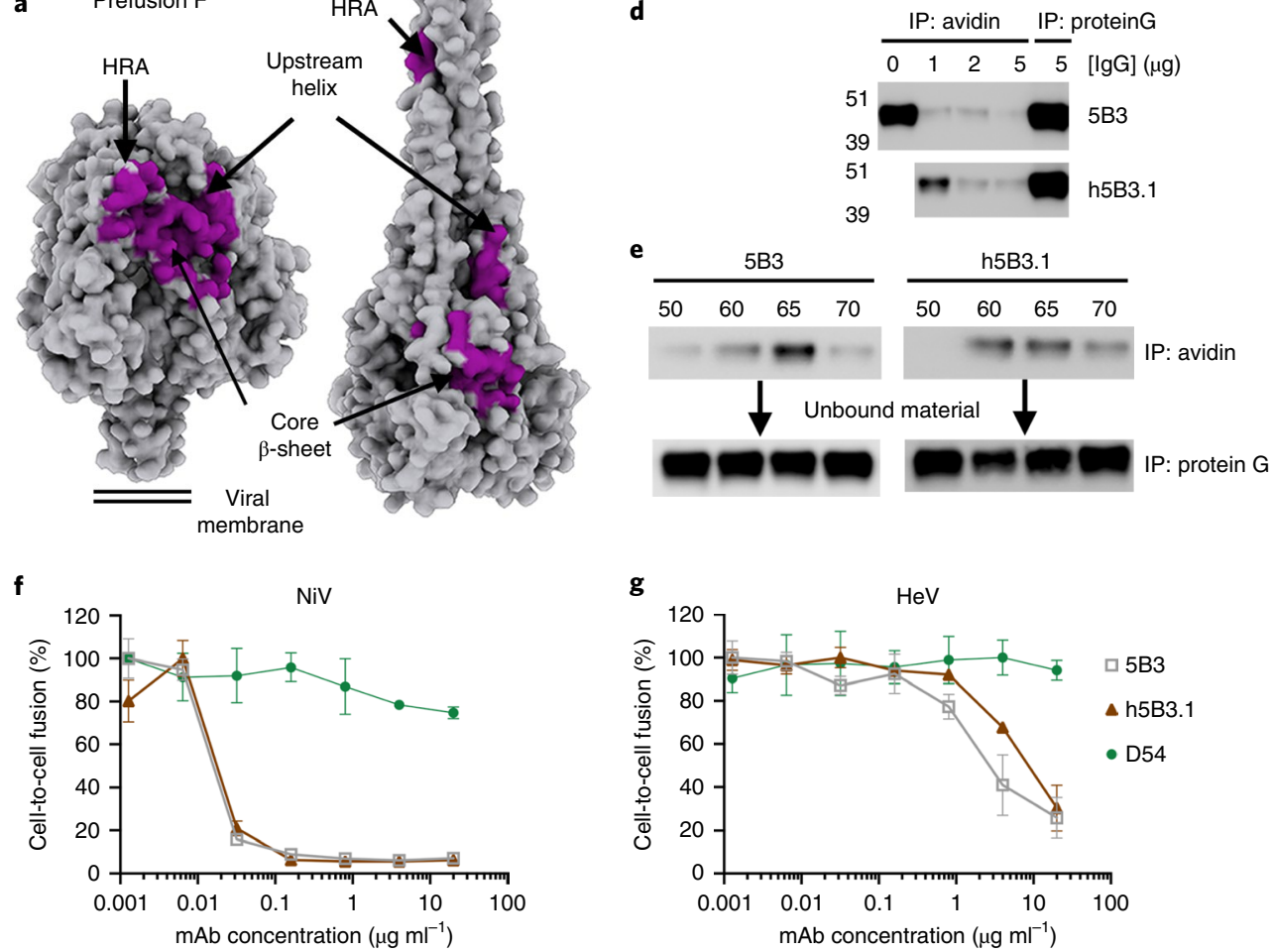

Fig. 4 | The 5B3 and h5B3.1 neutralizing antibodies inhibit fusion by locking NiV F in the prefusion state. a, Molecular surface representation of the $\mathrm{NiV} F$ prefusion trimer showing the 5B3 footprint colored violet. $\mathbf{b}$, Molecular surface representation of a homology model of the NiV F postfusion trimer showing the $5 \mathrm{~B} 3$ footprint colored violet. Upon refolding, the $5 \mathrm{~B} 3$ epitope is reorganized. The latter model was obtained by threading the NiV $\mathrm{F}$ sequence onto the human parainfluenza virus 3 postfusion $\mathrm{F}$ structure ${ }^{20}$ (PDB 1ZTM). c, 5B3 concentration-dependent inhibition of streptavidin-mediated pulldown of a biotinylated HRB/NiV F conformational intermediate complex in a triggering assay. The non-neutralizing control antibody (13G5), which is specific for postfusion F, had no effect. d, NiV F triggering assay carried out in the presence of 5B3 or h5B3.1 IgGs showing both mAbs prevented F fusogenic conformational changes. Subsequent protein $\mathrm{G}$ immunoprecipitation of F/5B3 and F/h5B3.1 complexes that were not pulled down by the biotinylated HRB peptide indicated the antibodies remain bound to $\mathrm{F}$. $\mathbf{e}$, Capture of an $\mathrm{F}$ fusogenic conformational intermediate could be partially rescued by raising the temperature to $\geq 60^{\circ} \mathrm{C}$, as detected by comparing streptavidin-mediated pulldown and protein $\mathrm{G}$ immunoprecipitation of $\mathrm{F} / 5 \mathrm{~B} 3$ and $\mathrm{F} / \mathrm{h} 5 \mathrm{~B} 3.1$ complexes. In $\mathbf{a}$ and $\mathbf{b}$, a single 5B3 epitope is colored for clarity. In all panels, precipitated samples were analyzed by western blotting using a rabbit anti-F antibody. $\mathbf{f}, \mathbf{g}$, NiV F (f) or HeV F (g) mediated cell-cell fusion could be inhibited by 5B3 or h5B3.1 in a concentration-dependent manner. D54 is an HIV envelope antibody used as negative control. Data shown are mean and s.d. for $n=2$ technical replicates. Uncropped images for $\mathbf{d}$ and $\mathbf{e}$ are available in the source data online.

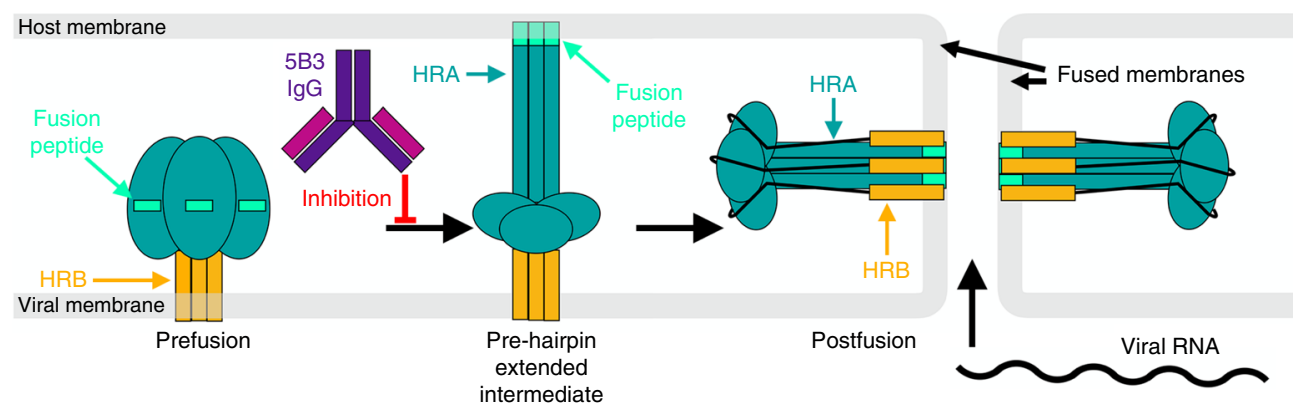

Fig. 5 | 5B3 and h5B3.1 neutralize NiV and HeV by inhibiting membrane fusion. Model of F-mediated membrane fusion. NiV (or HeV) F forms metastable homotrimers at the viral surface. Upon interaction between NiV (or HeV) G and ephrinB2/B3, F undergoes large-scale conformational changes leading to insertion of the fusion peptide in the host cell membrane by forming a hypothetical pre-hairpin extended intermediate conformation ${ }^{16}$. Subsequent $\mathrm{F}$ refolding leads to the postfusion conformation and merger of the viral and host membranes. Addition of $5 \mathrm{~B} 3$ or h5B3.1 locks $\mathrm{F}$ in the prefusion conformation and inhibits membrane fusion. 
So far, m102.4 is the only human mAb that has been used for $\mathrm{HNV}$ protection studies in ferrets and African green monkeys ${ }^{29-31}$. Murine antibodies have limited clinical use due to their short serum half-life, inability to trigger human effector functions and the risk of mounting an anti-mouse antibody response. We successfully engineered a humanized version of 5B3 (termed h5B3.1), which retained comparable breadth and potency to the parental mouse mAb and inhibited F-mediated membrane fusion. Therefore, similar to the anti-HNV G m102.4 neutralizing mAb, h5B3.1 could potentially be used for prophylaxis or for post-exposure therapy with individuals exposed to $\mathrm{NiV}$ or $\mathrm{HeV}$. Between 2010 and 2017, m102.4 was used on a compassionate basis to treat individuals with significant $\mathrm{HeV}$ or NiV exposure risk in Australia, the USA and India (https://www. who.int/blueprint/priority-diseases/key-action/nipah/en/). These individuals showed no evidence of infection or known health complications after administration of the mAb. The fact that m102.4 was used in humans despite the lack of clinical trials or approval by the FDA (or equivalent agencies) emphasizes the urgent need for developing therapeutics and other counter-measures against highly pathogenic HNVs that have fatality rates of $50-100 \%$.

Escape mutants have been isolated upon HNV passaging with m102. $4^{39}$ or with $5 \mathrm{~B} 3$ (here), but they have never been observed during $\mathrm{m} 102.4$ in vivo efficacy tests against $\mathrm{NiV}$ or $\mathrm{HeV}$, putatively due to the very high doses of antibodies utilized in those experiments in conjunction with the effective adaptive immune responses of the subjects. We postulate that similar outcomes could be expected with comparably high doses of 5B3/h5B3.1 mAbs. Furthermore, neutralization escape mutations to such an F-specific mAb could have a potentially negative impact on viral growth, replication and virulence, as observed with mutants obtained with anti-G antibodies ${ }^{28}$. Finally, the use of antibody cocktails has been proposed for Ebola virus ${ }^{50-52}$ or severe acute respiratory syndrome coronavirus (SARS-CoV) ${ }^{53}$ and implemented as a commercially available therapeutic for hepatitis $\mathrm{C}$ virus (XTL-6865, XTL Biopharmaceuticals) to prevent and/or limit the emergence of such mutants as well as enhance neutralization breadth. We suggest a similar strategy: combining h5B3.1 and m102.4 or other anti-HNV mAbs, targeting multiple antigenic sites on $\mathrm{G}$ and $\mathrm{F}$, could be implemented for treating future $\mathrm{NiV}$ and $\mathrm{HeV}$ infections.

\section{Online content}

Any methods, additional references, Nature Research reporting summaries, source data, statements of code and data availability and associated accession codes are available at https://doi.org/10.1038/ s41594-019-0308-9.

Received: 9 August 2019; Accepted: 21 August 2019; Published online: 30 September 2019

\section{References}

1. Eaton, B. T., Broder, C. C., Middleton, D. \& Wang, L. F. Hendra and Nipah viruses: different and dangerous. Nat. Rev. Microbiol. 4, 23-35 (2006).

2. Beineke, A., Baumgartner, W. \& Wohlsein, P. Cross-species transmission of canine distemper virus-an update. One Health 1, 49-59 (2015).

3. Clayton, B. A., Wang, L. F. \& Marsh, G. A. Henipaviruses: an updated review focusing on the pteropid reservoir and features of transmission. Zoonoses Public Health 60, 69-83 (2013).

4. Broder, C. C., Weir, D. L. \& Reid, P. A. Hendra virus and Nipah virus animal vaccines. Vaccine 34, 3525-3534 (2016).

5. Luby, S. P. \& Gurley, E. S. Epidemiology of Henipavirus disease in humans. Curr. Top. Microbiol. Immunol. 359, 25-40 (2012).

6. Arunkumar, G. et al. Outbreak investigation of Nipah virus disease in Kerala, India, 2018. J. Infect. Dis. 219, 1867-1878 (2018).

7. Pernet, O. et al. Evidence for henipavirus spillover into human populations in Africa. Nat. Commun. 5, 5342 (2014)

8. Wong, J. J. W. et al. Monomeric ephrinB2 binding induces allosteric changes in Nipah virus G that precede its full activation. Nat. Commun. 8, 781 (2017).

9. $\mathrm{Xu}, \mathrm{K}$. et al. Host cell recognition by the henipaviruses: crystal structures of the Nipah G attachment glycoprotein and its complex with ephrin-B3. Proc. Natl Acad. Sci. USA 105, 9953-9958 (2008).
10. Negrete, O. A. et al. EphrinB2 is the entry receptor for Nipah virus, an emergent deadly paramyxovirus. Nature 436, 401-405 (2005).

11. Bowden, T. A. et al. Structural basis of Nipah and Hendra virus attachment to their cell-surface receptor ephrin-B2. Nat. Struct. Mol. Biol. 15, 567-572 (2008)

12. Bonaparte, M. I. et al. Ephrin-B2 ligand is a functional receptor for Hendra virus and Nipah virus. Proc. Natl Acad. Sci. USA 102, 10652-10657 (2005).

13. $\mathrm{Xu}, \mathrm{K}$. et al. Crystal structure of the pre-fusion nipah virus fusion glycoprotein reveals a novel hexamer-of-trimers assembly. PLoS Pathog. 11, e1005322 (2015)

14. Pager, C. T., Craft, W. W. Jr, Patch, J. \& Dutch, R. E. A mature and fusogenic form of the Nipah virus fusion protein requires proteolytic processing by cathepsin L. Virology 346, 251-257 (2006).

15. Pager, C. T. \& Dutch, R. E. Cathepsin L is involved in proteolytic processing of the Hendra virus fusion protein. J. Virol. 79, 12714-12720 (2005).

16. Harrison, S. C. Viral membrane fusion. Nat. Struct. Mol. Biol. 15, 690-698 (2008)

17. Chan, Y. P. et al. Biochemical, conformational and immunogenic analysis of soluble trimeric forms of Henipavirus fusion glycoproteins. J. Virol. 86, 11457-11471 (2012)

18. Liu, Q. et al. Unraveling a three-step spatiotemporal mechanism of triggering of receptor-induced Nipah virus fusion and cell entry. PLoS Pathog. 9, e1003770 (2013)

19. Connolly, S. A., Leser, G. P., Yin, H. S., Jardetzky, T. S. \& Lamb, R. A. Refolding of a paramyxovirus $\mathrm{F}$ protein from prefusion to postfusion conformations observed by liposome binding and electron microscopy Proc. Natl Acad. Sci. USA 103, 17903-17908 (2006).

20. Yin, H. S., Paterson, R. G., Wen, X., Lamb, R. A. \& Jardetzky, T. S. Structure of the uncleaved ectodomain of the paramyxovirus (hPIV3) fusion protein. Proc. Natl Acad. Sci. USA 102, 9288-9293 (2005).

21. Yin, H. S., Wen, X., Paterson, R. G., Lamb, R. A. \& Jardetzky, T. S. Structure of the parainfluenza virus $5 \mathrm{~F}$ protein in its metastable, prefusion conformation. Nature 439, 38-44 (2006).

22. McLellan, J. S. et al. Structure of RSV fusion glycoprotein trimer bound to a prefusion-specific neutralizing antibody. Science 340, 1113-1117 (2013).

23. McLellan, J. S., Yang, Y., Graham, B. S. \& Kwong, P. D. Structure of respiratory syncytial virus fusion glycoprotein in the postfusion conformation reveals preservation of neutralizing epitopes. J. Virol. 85, 7788-7796 (2011).

24. Swanson, K. A. et al. Structural basis for immunization with postfusion respiratory syncytial virus fusion F glycoprotein (RSV F) to elicit high neutralizing antibody titers. Proc. Natl Acad. Sci. USA 108, 9619-9624 (2011)

25. Griffin, D. E. Immune responses during measles virus infection. Curr. Top. Microbiol. Immunol. 191, 117-134 (1995).

26. Zhu, Z. et al. Exceptionally potent cross-reactive neutralization of Nipah and Hendra viruses by a human monoclonal antibody. J. Infect. Dis. 197, 846-853 (2008).

27. Zhu, Z. et al. Potent neutralization of Hendra and Nipah viruses by human monoclonal antibodies. J. Virol. 80, 891-899 (2006).

28. Borisevich, V. et al. Escape from monoclonal antibody neutralization affects Henipavirus fitness in vitro and in vivo. J. Infect. Dis. 213, 448-455 (2016).

29. Bossart, K. N. et al. A neutralizing human monoclonal antibody protects against lethal disease in a new ferret model of acute Nipah virus infection. PLoS Pathog. 5, e1000642 (2009).

30. Bossart, K. N. et al. A neutralizing human monoclonal antibody protects african green monkeys from Hendra virus challenge. Sci. Transl. Med. 3, 105 ra103 (2011)

31. Geisbert, T. W. et al. Therapeutic treatment of Nipah virus infection in nonhuman primates with a neutralizing human monoclonal antibody. Sci. Transl. Med. 6, 242ra82 (2014).

32. Mire, C. E. et al. Pathogenic differences between Nipah virus Bangladesh and Malaysia strains in primates: implications for antibody therapy. Sci. Rep. 6, 30916 (2016).

33. Guillaume, V. et al. Antibody prophylaxis and therapy against Nipah virus infection in hamsters. J. Virol. 80, 1972-1978 (2006).

34. Guillaume, V. et al. Acute Hendra virus infection: analysis of the pathogenesis and passive antibody protection in the hamster model. Virology 387, 459-465 (2009)

35. Broder, C. C. et al. Immunization strategies against henipaviruses. Curr. Top. Microbiol. Immunol. 359, 197-223 (2012).

36. Aguilar, H. C. et al. N-glycans on Nipah virus fusion protein protect against neutralization but reduce membrane fusion and viral entry. J. Virol. 80, 4878-4889 (2006)

37. Carter, J. R., Pager, C. T., Fowler, S. D. \& Dutch, R. E. Role of N-linked glycosylation of the Hendra virus fusion protein. J. Virol. 79, 7922-7925 (2005).

38. Moll, M., Kaufmann, A. \& Maisner, A. Influence of N-glycans on processing and biological activity of the Nipah virus fusion protein. J. Virol. 78, 7274-7278 (2004)

39. Xu, K. et al. Crystal structure of the Hendra virus attachment G glycoprotein bound to a potent cross-reactive neutralizing human monoclonal antibody. PLoS Pathog. 9, e1003684 (2013). 
40. Lee, J. K., Prussia, A., Snyder, J. P. \& Plemper, R. K. Reversible inhibition of the fusion activity of measles virus $F$ protein by an engineered intersubunit disulfide bridge. J. Virol. 81, 8821-8826 (2007).

41. McLellan, J. S. et al. Structure-based design of a fusion glycoprotein vaccine for respiratory syncytial virus. Science 342, 592-598 (2013).

42. Wong, J. J., Paterson, R. G., Lamb, R. A. \& Jardetzky, T. S. Structure and stabilization of the Hendra virus F glycoprotein in its prefusion form. Proc. Natl Acad. Sci. USA 113, 1056-1061 (2016).

43. Stewart-Jones, G. B. E. et al. Structure-based design of a quadrivalent fusion glycoprotein vaccine for human parainfluenza virus types 1-4. Proc. Natl Acad. Sci. USA 115, 12265-12270 (2018).

44. Bossart, K. N. et al. Inhibition of Henipavirus fusion and infection by heptadderived peptides of the Nipah virus fusion glycoprotein. Virol. J. 2, 57 (2005).

45. Bossart, K. N. et al. Membrane fusion tropism and heterotypic functional activities of the Nipah virus and Hendra virus envelope glycoproteins. J. Virol. 76, 11186-11198 (2002).

46. Sastre, P., Melero, J. A., Garcia-Barreno, B. \& Palomo, C. Comparison of affinity chromatography and adsorption to vaccinia virus recombinant infected cells for depletion of antibodies directed against respiratory syncytial virus glycoproteins present in a human immunoglobulin preparation. J. Med. Virol. 76, 248-255 (2005).

47. Krarup, A. et al. A highly stable prefusion RSV F vaccine derived from structural analysis of the fusion mechanism. Nat. Commun. 6, 8143 (2015).

48. Marcandalli, J. et al. Induction of potent neutralizing antibody responses by a designed protein nanoparticle vaccine for respiratory syncytial virus. Cell $\mathbf{1 7 6}$ 1420-1431.e17 (2019).

49. Battles, M. B. et al. Structure and immunogenicity of pre-fusion-stabilized human metapneumovirus F glycoprotein. Nat. Commun. 8, 1528 (2017).

50. Qiu, X. et al. Reversion of advanced Ebola virus disease in nonhuman primates with ZMapp. Nature 514, 47-53 (2014).

51. Wec, A. Z. et al. Development of a human antibody cocktail that deploys multiple functions to confer pan-ebolavirus protection. Cell Host Microbe 25, 39-48.e5 (2019).

52. Bornholdt, Z. A. et al. A two-antibody pan-ebolavirus cocktail confers broad therapeutic protection in ferrets and nonhuman primates. Cell Host Microbe 25, 49-58.e5 (2019).

53. Rockx, B. et al. Escape from human monoclonal antibody neutralization affects in vitro and in vivo fitness of severe acute respiratory syndrome coronavirus. J. Infect. Dis. 201, 946-955 (2010).

\section{Acknowledgements}

We thank M.M. Sauer for his assistance with biolayer interferometry assays and $\mathrm{N}$. Zheng for providing access to his crystallization robot. This study was supported by the National Institute of Allergy and Infectious Diseases (D.V., HHSN272201700059C; C.C.B., AI054715, AI077995 and AI142764), the National Institute of General Medical Sciences (D.V., GM120553), an Investigators in the Pathogenesis of Infectious Disease Award from the Burroughs Wellcome Fund (D.V.), a Pew Biomedical Scholars Award (D.V.), the Netherlands Organization for Scientific Research (J.S., Rubicon 019.2015.2.310.006), the European Molecular Biology Organisation (J.S., ALTF9332015), the University of Washington Arnold and Mabel Beckman cryo-EM center and Proteomics Resource (UWPR95794) and Beamline 5.0.1 at the Advanced Light Source at Lawrence Berkley National Laboratory, which is a Department of Energy Office of Science User Facility under contract no. DE-AC02-05CH11231 and is supported by the Howard Hughes Medical Institute and NIH grant no. S10OD021832.

\section{Author contributions}

H.V.D., Y.-P.C., Y.-J.P., J.S., C.E.M., C.C.B. and D.V. designed the experiments. H.V.D. and Y.-P.C. designed and cloned the protein constructs. Y.-P.C. and S.C.D.S. performed the fusion assays. H.V.D., Y.-P.C., L.Y. and Y.-R.F. expressed and purified the proteins used in this study. Y.-P.C. and B.V. humanized 5B3 and generated stable cell lines. H.V.D., Y.-J.P. and D.V. performed cryo-EM sample preparation, data collection, processing, model building and refinement. H.V.D. and Y.-J.P. crystallized 5B3, collected and processed the data, and built and refined the atomic model. H.V.D., Y.-P.C. and B.V. performed all binding assays. T.G. and C.E.M. carried out the neutralization assays. B.R. isolated the neutralization escape mutants. H.V.D., Y.-P.C., Y.-J.P., J.S., C.E.M., C.C.B. and D.V. analyzed the data. H.V.D., Y.-P.C., C.C.B. and D.V. prepared the manuscript, with input from all authors.

\section{Competing interests}

Y.P.C. and C.B. are inventors on US patent 2016/0347827 Al 'Antibodies against F glycoprotein of Hendra and Nipah viruses'.

\section{Additional information}

Extended data is available for this paper at https://doi.org/10.1038/s41594-019-0308-9.

Supplementary information is available for this paper at https://doi.org/10.1038/ s41594-019-0308-9.

Correspondence and requests for materials should be addressed to C.C.B. or D.V. Peer review information Inês Chen was the primary editor on this article and managed its editorial process and peer review in collaboration with the rest of the editorial team. Reprints and permissions information is available at www.nature.com/reprints. Publisher's note Springer Nature remains neutral with regard to jurisdictional claims in published maps and institutional affiliations.

(c) The Author(s), under exclusive licence to Springer Nature America, Inc. 2019 


\section{Methods}

Cell lines. HEK293F cells (Life Technologies) were grown in 293FreeStyle expression medium (Life Technologies), cultured at $37^{\circ} \mathrm{C}$ with $5 \% \mathrm{CO}_{2}$ and 150 r.p.m. HEK293T/17 is a female human embryonic kidney cell line (ATCC) HEK293T/17 cells (kind gift from G. Quinnan) were cultured at $37^{\circ} \mathrm{C}$ with $5 \%$ $\mathrm{CO}_{2}$ in flasks with DMEM + 10\% FBS + penicillin-streptomycin + $10 \mathrm{mM}$ HEPES. VeroE6 cells (ATCC) were grown in serum-free medium (VP-SFM, ThermoFisher) at $37^{\circ} \mathrm{C}$ and $5 \% \mathrm{CO}_{2}$. HeLa-USU and HeLa-ATCC (ATCC) cells ${ }^{12}$ were maintained in DMEM (Quality Biologicals), supplemented with $10 \%$ Cosmic calf serum (HyClone), and $2 \mathrm{mM}$ L-glutamine. HeLa-USU cells, ephrin-B2 and ephrin-B3 negative, (kind gift from A. Maurelli, Uniformed Services University) and HeLa-CCL2, ephrin-B2 positive (ATCC), have previously undergone cytogenetic analysis. Other cell lines were not authenticated. Cells were not tested for mycoplasma contamination.

Antibodies and peptides. The rabbit anti-F polyclonal antibody was produced by Spring Valley Laboratories using the NiV F ectodomain trimer fused to GCN4 as an immunogen. The horseradish peroxidase-conjugated rabbit anti-S-peptide antibody was purchased from Bethyl Laboratories. Anti-F murine monoclonal antibodies were produced as previously described ${ }^{17}$.

The N-terminal biotinylated NiV F HRB peptide (residues $453-488)^{44}$ was synthesized by Global Peptide Services.

NiV F and $\mathrm{HeV}$ F construct. The NiV F and $\mathrm{HeV} F$ ectodomain constructs used for biolayer interferometry and NiV F triggering assay include the codon optimized NiV F (isolate UMMC1; GenBank sequence accession no. AY029767) or $\mathrm{HeV} \mathrm{F}$ (isolate Horse/Australia/Hendra/1994) ectodomain (residues 1-487) fused to a C-terminal GCN4 followed by a factor Xa sequence and an S-tag (KLKETAAAKFERQHMDS) cloned in a pcDNA Hygro (+)-CMV+ vector for transient expression using FreeStyle 293F cells. For epitope mapping, conversion of specific residues of $\mathrm{NiV} F$ to alanine, serine, glutamic acid or aspartic acid was performed via site-directed mutagenesis using the Quick-Change II Sitedirected Mutagenesis Kit (Stratagene). The template for the reactions consisted of a C-terminal S-peptide tagged version of the codon optimized full-length NiV F (UMMC1 isolate) cloned in the pcDNA Hygro (+)-CMV+ vector. All mutationcontaining constructs were sequence verified.

The NiV F ectodomain construct used for cryo-EM experiments includes a human codon-optimized NiV F ectodomain trimer (amino acid residues 1-494) with a FLAG tag (DYKDDDK) introduced between residues L104-V105 and a C-terminal GCN4 motif (a kind gift from H. Aguilar-Carreno). This construct was engineered by subcloning into a pBS SK $(+)$ vector and introducing the previously described N100C/A119C substitutions ${ }^{42}$ by site-directed mutagenesis using a QuikChange kit (Agilent) before subsequent subcloning into a pCAGGs vector for transient expression in FreeStyle 293F cells.

Cloning and sequencing of $\mathbf{m A b} 5 \mathrm{B3}$ cDNA. The 5B3 cDNA was amplified from hybridomas using a SuperScript III Cells Direct cDNA Synthesis Kit (Invitrogen) with random hexamer and IgG2-specific primers ${ }^{54}$. PCR amplification of $\mathrm{VH}$ and VL was performed using the cDNA as a template and degenerate forward primers for the signal sequence or the conserved framework 1 (FR1) of the VH- and VLencoding sequences and reverse primers for the FR4 or the $3^{\prime}$ end of the constant heavy chain 1 (CH1)- and constant light chain (CL)-encoding sequences ${ }^{54,55}$. The PCR products were cloned into pCR-Blunt II-TOPO vector (Invitrogen) and transformed into one Shot TOP10 chemically competent Escherichia coli (Invitrogen). Plasmids were extracted from colonies and the cloned PCR products were sequenced using M13 forward and reverse primers.

Humanization of 5B3 to generate h5B3 and h5B3.1. To engineer a humanized version of 5B3, a human scFv library was first generated based on FR1 and FR4 sequence similarity with 5B3. We adapted previously described methods and PCR primers employed for the generation of naive human $\mathrm{scFv}$ library constructed from peripheral blood B cells of several healthy donors ${ }^{56}$ by using only the VH subfamily III and $\kappa$ VL subfamily I primers. VH and VL were first amplified separately from the IgM cDNA library. For VH, we used forward and reverse primers probing the FR1 and FR4 of VH III with restriction site SfiI added to the $5^{\prime}$ end of the forward primer and $\left(\mathrm{G}_{4} \mathrm{~S}\right)_{3}$ linker sequence added to the $3^{\prime}$ end of the reverse primer. For VL, we used forward and reverse primers probing the FR1 and FR4 of VLK I with $\left(\mathrm{G}_{4} \mathrm{~S}\right)_{3}$ linker sequence added to the $5^{\prime}$ end of the forward primer and restriction site $S f i \mathrm{I}$ added to the $3^{\prime}$ end of the reverse primer. The scFv library was assembled by overlapping PCR combining the VH and VL PCR products as template and using the VH III FR1 SfiI forward and VLא I FR4 SfiI reverse primers. The amplified scFv was then cloned into a pCom $3 \mathrm{X}$ vector harboring a C-terminal hexa-histidine tag. Colonies from the scFv library were grown and expressed as previously described ${ }^{57}$. We selected the 12 best expressing clones for DNA sequencing based on Coomassie blue staining and western blot analysis using an anti-histidine tag antibody. The translated human scFv FR sequences were then aligned against that of 5B3. For humanization of 5B3, conserved human residues from the alignment were identified and replaced into the homologous positions of $5 \mathrm{~B} 3$ to generate h5B3. To further humanize h5B3, a version named h5B3.1 was generated from h5B3 where one residue on each of the CDR1 and CDR2 and two residues on CDR3 were mutated into conserved human residues based on the sequences from the human scFv library mentioned above.

scFv and IgG1 constructs. The scFv constructs were designed with VH and VL separated by a flexible linker $\left(\mathrm{G}_{4} \mathrm{~S}\right)_{3}$, codon-optimized, synthesized by Genscript and cloned into a promoter-modified pcDNA Hygro (+)-CMV+vector ${ }^{58}$ with a immunoglobulin $\kappa$ chain leader sequence and a C-terminal S-peptide tag followed by a hexa-histidine tag.

For IgG constructs, $\mathrm{VH}$ and $\mathrm{VL}$ were cloned into a $\mathrm{pDR} 12$ vector that harbors the $\kappa \mathrm{CL}$ and IgG1 $\mathrm{CH}$ fragments as separate open reading frames with independent promoters ${ }^{59}$. Subsequently, the entire expression cassette of the heavy and light chain of pDR12-h5B3.1 was amplified and sub-cloned into pcDNA Hygro (+)-CMV+ vector for the development of stable cell lines.

Generation of scFv- and IgG1-expressing stable cell lines. HEK 293T cells grown in D-10 were transfected with different scFv or IgG1 constructs using Fugene transfection reagent (Roche Diagnostics). Cells were transfected with $2 \mu \mathrm{g}$ DNA and $6 \mu \mathrm{l}$ Fugene per well of a $60 \%$ confluent six-well tissue culture plate following the manufacturer's instructions. At $48 \mathrm{~h}$ post transfection, the culture medium was either replaced with selection medium (D-10 supplemented with $150 \mu \mathrm{g} \mathrm{ml}^{-1}$ of hygromycin B, Invitrogen) for stable cell line development or harvested for S-protein agarose (EMD Biosciences) or Ni-NTA agarose (QIAGEN) precipitation for transient expression evaluation. To generate a cell line for stable expression, hygromycin-resistant cells were then subjected to two rounds of limiting dilution cloning, as previously described ${ }^{58}$.

Large-scale expression and purification of IgG1. Production and purification of mouse IgGs (5B3, 12B2 and 13G5) from hybridomas was carried out as previously described ${ }^{17}$

Transient expression of h5B3.1 IgG1 was carried out by transfecting FreeStyle 293F suspension cells in serum-free FreeStyle 293 expression medium (Invitrogen) in shaker flasks at a density of $1 \times 10^{6}$ cells $\mathrm{ml}^{-1}$ using $293 \mathrm{fectin}$ transfection reagent (Invitrogen) following the manufacturer's protocol. Production of h5B3.1 IgG1 from a stable cell line was carried out by culturing the FreeStyle $293 \mathrm{~F}$ cells expressing h5B3.1 IgG1 in $70 \mathrm{ml}$ of FreeStyle 293 expression medium in $500 \mathrm{ml}$ shaker flasks at a density of $1 \times 10^{6} \mathrm{cells} \mathrm{ml}^{-1}$. The transfected cells or stable cells were allowed to grow for an additional 3-4 days with $50 \mathrm{ml}$ of culture medium added for every subsequent day.

Culture supernatants expressing IgG were collected and centrifuged at $4{ }^{\circ} \mathrm{C}$ for $15 \mathrm{~min}$ at $5,000 \mathrm{~g}$. The supernatant was then filtered through a $0.2 \mu \mathrm{m}$ low protein binding membrane (Corning) and passed through a HiTrap Protein G HP column (GE Healthcare Biosciences) equilibrated in phosphate-buffered saline (Quality Biologicals). The column was washed with five column volumes of phosphatebuffered saline. The bound $\mathrm{mAb}$ was eluted with $0.1 \mathrm{M}$ glycine $\mathrm{pH} 2$ followed by immediate neutralization with $1 \mathrm{M}$ Tris $\mathrm{pH} 8.0$, concentrated, and bufferexchanged into phosphate-buffered saline using an Amicon Ultra centrifugal concentrator (Millipore).

Generation of Fab fragments from IgG. The 5B3 Fab was obtained by fragmentation of mouse 5B3 IgG using Pierce mouse IgG1 Fab and F( $\left.\mathrm{ab}^{\prime}\right) 2$ preparation kits according to the manufacturer's protocol.

The h5B3.1 Fab fragment was obtained by fragmentation of h5B3.1 IgG with Lys-C protease (EMD Millipore) and affinity purification using protein A agarose resin (Genscript). Briefly, $1.0 \mathrm{mg}$ IgG was incubated with $0.5 \mu \mathrm{g}$ Lys-C for $7 \mathrm{~h}$ at $37^{\circ} \mathrm{C}$. The reaction was quenched by addition of PMSF to $1 \mathrm{mM}$ final concentration and the undigested and $\mathrm{Fc}$-containing portion of the sample was removed using a protein A resin. The Fab-containing flow-through from the protein A affinity step was collected.

The Fab-containing fraction was concentrated and further purified using a Superdex 75 10/300 gel filtration column equilibrated in a buffer containing $50 \mathrm{mM}$ Tris $\mathrm{pH} 8.0$ and $150 \mathrm{mM} \mathrm{NaCl}$.

NiV F and HeV F ectodomain production. Soluble NiV F and $\mathrm{HeV} F$ were produced by transient transfection of FreeStyle $293 \mathrm{~F}$ cells at a density of $1 \times 10^{6}$ cells $\mathrm{ml}^{-1}$ with the corresponding plasmid using 293 -Free transfection reagent (Millipore) and Opti-MEM (Thermo-Fisher) according to the manufacturer's protocol. After five days in a humidified shaking incubator, maintained at $37^{\circ} \mathrm{C}$ and $8 \% \mathrm{CO}_{2}$, the cell supernatant was harvested and clarified of cell debris by centrifugation. Subsequent affinity purification was carried out using an anti-FLAG resin (Genscript) and elution with $1 \mathrm{mg} \mathrm{ml}^{-1}$ FLAG peptide dissolved in Tris buffer $\mathrm{pH} 8.0,150 \mathrm{mM} \mathrm{NaCl}$ or with S-protein agarose (Millipore Sigma, Novagen) and elution with $0.2 \mathrm{M}$ citric acid $\mathrm{pH} 2.0$ followed by immediate neutralization with $1.0 \mathrm{M}$ Tris $\mathrm{pH}$ 9.5. The eluted fraction was buffer-exchanged into $50 \mathrm{mM}$ Tris buffer $\mathrm{pH} 8.0,150 \mathrm{mM} \mathrm{NaCl}$ using a $30 \mathrm{kDa}$ cutoff centrifugal concentrator (Millipore).

Biolayer interferometry. Assays were performed with an Octet Red 96 instrument (ForteBio) at $30^{\circ} \mathrm{C}$ while shaking at 1,000 r.p.m. All measurements 
were corrected by subtracting the background signal obtained from biosensors without immobilized $\mathrm{HeV}$ F or NiV F. S-peptide tagged $\mathrm{HeV}$ F or NiV F in phosphate buffered saline at $\mathrm{pH} 7.4$ was diluted to $14 \mu \mathrm{g} \mathrm{ml}^{-1}$ in $10 \mathrm{mM}$ acetate buffer pH 5.0 before immobilization on $N$-hydroxysuccinimide-(1-ethyl-3-(3dimethylaminopropyl)carbodiimide hydrochloride (NHS-EDC). NHS-EDCactivated Amine Reactive 2nd Generation (AR2G, ForteBio) biosensors for $300 \mathrm{~s}$. The sensors were then quenched in $1 \mathrm{M}$ ethanolamine (ForteBio) for $300 \mathrm{~s}$ and incubated in kinetics buffer (KB: $1 \times$ PBS, $0.01 \%$ BSA, $0.02 \%$ Tween 20 and $0.005 \%$ $\mathrm{NaN}_{3}$ (ForteBio)) for $300 \mathrm{~s}$ to establish the baseline signal (nm shift). HeV F- or $\mathrm{NiV}$ F-loaded sensors were then immersed in solutions of purified Fab (5B3 or h5B3.1) diluted in KB to the desired concentrations for kinetics analysis (300$1.23 \mathrm{nM}$ for 5B3 Fab and 900-3.7 $\mathrm{nM}$ for h5B3.1 Fab). Curve fitting was performed using a 1:1 binding model to determine the binding kinetics with ForteBio data analysis software. Mean $k_{\text {on }}$ and $k_{\text {off }}$ values were determined with a global fit applied to all data. Experiments were performed twice with independent $\mathrm{NiV} \mathrm{F}$ and $\mathrm{HeV} \mathrm{F}$ protein preparations, yielding identical results and kinetic parameters.

\section{Crystallization, data collection and processing of the 5B3 Fab. Crystals were} grown in hanging drops set up with a mosquito at $20^{\circ} \mathrm{C}$ using $150 \mathrm{nl}$ protein solution and $150 \mathrm{nl}$ mother liquor containing $0.2 \mathrm{M}$ magnesium chloride, $0.1 \mathrm{M}$ Tris- $\mathrm{HCl} \mathrm{pH} 8.5$ and 20\% PEG 8000. The diffraction dataset was collected at ALS beamline 5.0.1 and processed to $1.5 \AA$ resolution using $\mathrm{XDS}^{60}$ and Aimless ${ }^{61}$. The structure was solved by molecular replacement using Phaser ${ }^{62}$ and S230 SARS-CoV $\mathrm{Fab}^{63}$ as search model. The coordinates were subsequently improved and completed using Buccaneer ${ }^{64}$ and COOT ${ }^{65}$ and refined with BUSTER-TNT ${ }^{66}$ and REFMAC $5^{67}$ The quality of the final model was analyzed using MolProbity ${ }^{68}$ (score 1.13) and Clashscore (3.35). The percentage of poor rotamers was $0.92 \%$; Ramachandran statistics were $98.84 \%$ favored and $100 \%$ allowed. Other crystallographic data collection and refinement statistics are summarized in Table 2.

Purification of the NiV F-5B3 complex. Purified FLAG-tagged NiV F N100C/ A119C ectodomain was combined with an excess molar ratio of 5B3 Fab and incubated on ice for $1 \mathrm{~h}$ before injection on a Superose 6 Increase 10/300 column (GE Healthcare) equilibrated in a buffer containing $50 \mathrm{mM}$ Tris $\mathrm{pH} 8.0$ and $150 \mathrm{mM} \mathrm{NaCl}$. The fractions containing the complex were quality-controlled by negative staining EM, pooled, buffer-exchanged and concentrated.

Cryo-electron microscopy specimen preparation and data collection. A $3 \mu \mathrm{l}$ volume of the purified FLAG-tagged NiV F N100C/A119C 5B3 Fab complex at a concentration of $0.1 \mathrm{mg} \mathrm{ml}^{-1}$ was applied onto glow-discharged C-flat $(\mathrm{Cu} 200$ mesh, CF-1.2/1.3, Protochips) holey carbon grids covered with a thin layer of continuous home-made carbon and incubated for $30 \mathrm{~s}$ on grids. Grids were then plunge-frozen in liquid ethane and cooled with liquid nitrogen, using an FEI MK4 Vitrobot with a $3.0 \mathrm{~s}$ blot time. The chamber was kept at $20^{\circ} \mathrm{C}$ and $100 \%$ humidity during the blotting process.

Data acquisition was carried out with the Leginon data collection software ${ }^{69}$ on an FEI Titan Krios electron microscope operated at $300 \mathrm{kV}$ and equipped with a Gatan BioQuantum energy filter (slit width of $20 \mathrm{eV}$ ) and a Gatan K2 Summit camera. The nominal magnification was $105,000 \times$ and the pixel size was $1.37 \AA$ The dose rate was adjusted to 8 counts per pixel per second and each video was acquired in counting mode fractionated in 50 frames of $200 \mathrm{~ms}$ each. A total of 2,686 micrographs were collected with a defocus range between 1.5 and $2.5 \mu \mathrm{m}$

Cryo-electron microscopy data processing. Video frame alignment was carried out with MotionCor $2^{70}$. Particles were automatically selected using DoG Picker within the Appion interface ${ }^{72}$. Initial defocus parameters were estimated with $\mathrm{GCTF}^{73}$. A total of 380,459 particles were picked, extracted and processed with a box size of 256 pixel $^{2}$ and preprocessed using Relion $3.0^{74}$. Reference-free twodimensional (2D) classification with cryoSPARC was used to select a subset of particles, which were used to generate an initial model using the Ab-Initio reconstruction function in cryoSPARC ${ }^{75}$. This $3 \mathrm{D}$ map was subsequently used as a reference for running $3 \mathrm{D}$ classification with C3 symmetry in Relion on the entire dataset. 262,879 particles were selected from the set of all picked particles for 3D refinement using Relion. CTF refinement in Relion 3.0 was used to refine per-particle defocus values and particle images were subjected to the Bayesian polishing procedure in Relion $3.0^{76}$ and $3 \mathrm{D}$ refinement before performing another round of CTF refinement and 3D refinement. The particles were subsequently subjected to another round of 3D classification in Relion 3.0 without refining angles and shifts. 38,756 particles from the best class (showing a resolved stem) were used for non-uniform refinement in CryoSPARC to obtain the final 3D reconstruction at $3.5 \AA$ resolution. Reported resolutions are based on the goldstandard FSC $=0.143$ criterion $^{77,78}$ and Fourier shell correlation curves were corrected for the effects of soft masking by high-resolution noise substitution ${ }^{79}$ Local resolution estimation and filtering was carried out using cryoSPARC. Data collection and processing parameters are listed in Table 1.

Model building and analysis. UCSF Chimera ${ }^{80}$ was used to rigid-body fit the crystal structures of the NiV F ectodomain ${ }^{13}$ and of the $5 \mathrm{~B} 3 \mathrm{Fab}$ crystal structure into the cryo-EM density. The model was subsequently rebuilt manually using
$\operatorname{Coot}^{81}$ and refined using Rosetta ${ }^{82-84}$. Glycan refinement relied on a dedicated Rosetta protocol, which uses physically realistic geometries based on prior knowledge of saccharide chemical properties ${ }^{85}$ and was aided by using both sharpened and unsharpened maps. Models were analyzed using MolProbity ${ }^{68}$, EMRinger ${ }^{86}$ and Privateer ${ }^{87}$. The refinement statistics are listed in Table 1. Figures were generated using UCSF ChimeraX ${ }^{88}$.

Immunoprecipitation. To evaluate the binding of NiV F mutants with different antibodies, sub-confluent HEK 293T cells were transfected with untagged full-length wild type or one of the mutant NiV F constructs using the Fugene transfection reagent, as described above. Cells were harvested at $48 \mathrm{~h}$ post transfection and were lysed in $500 \mu \mathrm{l}$ buffer containing $0.1 \mathrm{M}$ Tris $\mathrm{pH} 8.0,0.1 \mathrm{M}$ $\mathrm{NaCl}$ supplemented with complete protease inhibitor cocktail (Roche) and clarified by centrifugation. Clarified lysates were added to $2 \mu \mathrm{g}$ of IgG followed by $50 \mu \mathrm{l}$ of $20 \%$ slurry protein $\mathrm{G}$ sepharose for samples incubated with IgGs or $30 \mu \mathrm{l}$ of $50 \%$ slurry S-protein agarose for those that were not.

To evaluate h5B3 chain binding to F, $300 \mu$ of clarified untagged full-length F-expressing HEK 293T cell lysate was added to the h5B3 scFv-expressing culture supernatants and precipitated with $30 \mu \mathrm{l}$ of $50 \%$ slurry of S-protein agarose.

In all cases, immunoprecipitation/pulldown were performed overnight at $4{ }^{\circ} \mathrm{C}$. The samples were washed three times with a buffer containing $1 \%$ Triton $\mathrm{X}-100,0.1 \mathrm{M}$ Tris $\mathrm{pH} 8.0,0.1 \mathrm{M} \mathrm{NaCl}$ and subsequently boiled in reducing SDSpolyacrylamide gel electrophoresis (PAGE) sample buffer followed by SDS-PAGE and western blot analyses.

HRB peptide triggering assay. The capture assay was performed as previously described ${ }^{17}$ with the addition of a competition step in the presence of increasing amounts of IgGs. Briefly, $1 \mu \mathrm{g}$ of purified S-peptide tagged NiV F ectodomain trimer was cleaved with $10 \mathrm{ng}$ of trypsin (New England Biolabs) in a $10 \mu \mathrm{l}$ reaction volume of buffer at $4{ }^{\circ} \mathrm{C}$ overnight to generate the mature $\mathrm{F} 1$ and $\mathrm{F} 2$ subunits. The reaction was stopped with $1 \mu \mathrm{l}$ of $10 \times$ complete protease inhibitor cocktail (Roche). Subsequently, $2 \mu$ g of biotinylated NiV F HRB peptide was added in the presence or absence of competing IgG. The sample was heated for $15 \mathrm{~min}$ at $50^{\circ} \mathrm{C}$, $60^{\circ} \mathrm{C}, 65^{\circ} \mathrm{C}$ or $70^{\circ} \mathrm{C}$ and the NiV F/HRB complex was subsequently pulled down using $30 \mu \mathrm{l}$ of $50 \%$ avidin-agarose slurry for $1 \mathrm{~h}$ at $4^{\circ} \mathrm{C}$ (Thermo Fisher Scientific). When indicated, the unbound fraction was pulled down with protein $\mathrm{G}$ sepharose. Samples were washed three times with a buffer containing $1 \%$ Triton X-100, $0.1 \mathrm{M}$ Tris $\mathrm{pH}$ 8.0, $0.1 \mathrm{M} \mathrm{NaCl}$ and boiled in $50 \mu \mathrm{l}$ of reducing SDS-PAGE sample buffer. To analyze the precipitated product, a $25 \mu \mathrm{l}$ sample was applied to a $4-12 \%$ BT SDS-PAGE (Invitrogen) followed by western blotting and detection using a rabbit anti-NiV F polyclonal antibody.

Cell-cell fusion assays. Fusion between NiV F and G glycoprotein-expressing effector cells and permissive target cells was measured using a previously described $\beta$-galactosidase assay ${ }^{89}$. Briefly, plasmids encoding S-peptide tagged wild-type $\mathrm{NiV} F$ or each mutant of F and NiV G or no DNA (control/mock transfection) were transfected into HeLa-USU effector cells using lipofectamine LTX with Plus reagent (Thermo-Fischer Scientific). The following day, transfected cells were infected with vaccinia virus-encoding T7 RNA polymerase. HeLa-ATCC cells served as receptor-positive target cells and were also infected with the E. coli Lac $\mathrm{Z}$-encoding reporter vaccinia virus. Cells were infected at a multiplicity of infection of 10 and incubated at $37^{\circ} \mathrm{C}$ overnight. Cell fusion reactions were conducted by incubating the target and effector cell mixtures at a ratio of $1: 1\left(2 \times 10^{5}\right.$ total cells per well; $0.2 \mathrm{ml}$ total volume) in 96 -well plates at $37^{\circ} \mathrm{C}$. Cytosine arabinoside ( $40 \mu \mathrm{g} \mathrm{ml}^{-1}$, Sigma-Aldrich) was added to the fusion reaction mixture to reduce non-specific $\beta$-galactosidase production. Nonidet P40 (EMD Millipore Sigma) was added ( $0.5 \%$ final concentration) at 2.5 or $3.0 \mathrm{~h}$, and aliquots of the lysates were assayed for $\beta$-galactosidase at ambient temperature with the substrate chlorophenol red-D-galactopyranoside (Roche). Assays were performed in triplicate, and fusion results were calculated and expressed as rates of $\beta$-Gal activity (change in optical density at $570 \mathrm{~nm} \mathrm{~min}^{-1} \times 1,000$ ) in a VersaMAX microplate reader (Molecular Devices). Equal amounts of leftover F/G-expressing effector cells from each fusion reaction were lysed and clarified by centrifugation. The lysates were then subjected to S-protein agarose precipitation followed by SDS-PAGE and western blotting to evaluate the expression level of each $\mathrm{F}$ mutant as compared to wild type. The individual cell fusion reactions mediated by each mutant were converted to percentages of wild-type fusion activity and normalized with the total expression of $\mathrm{F}$ and each $\mathrm{F}$ mutant as measured by densitometry from the images of western blot bands using ImageQuantTL software (GE Healthcare Biosciences). Normalization of each F mutant percentage of wild-type fusion was calculated with the formula: normalized percentage of wild-type fusion $=(100 /$ percentage of wild-type expression) $\times$ percentage of wild-type fusion.

$\mathrm{NiV}$ and $\mathrm{HeV} \mathrm{F}$ mAb neutralization assays. The virus infectivity neutralization concentrations of a control antibody D10 IgG2a anti-HIV gp41 ${ }^{90}, 5 \mathrm{~B} 3 \mathrm{IgG}$ anti-F and h5B3.1 IgG1 anti-F were determined for $\mathrm{NiV}$ and $\mathrm{HeV}$ using a plaque reduction assay. Briefly, antibodies were serially diluted fivefold from $150 \mu \mathrm{g} \mathrm{ml}^{-1}$ to $1.9 \mathrm{ng} \mathrm{ml}^{-1}$ and incubated with a target of $\sim 100$ p.f.u. (plaque-forming units) of $\mathrm{NiV}-\mathrm{M}, \mathrm{NiV}-\mathrm{B}$ or $\mathrm{HeV}$ for $45 \mathrm{~min}$ at $37^{\circ} \mathrm{C}$. Virus and antibody mixtures were then 
added to individual wells of six-well plates of VeroE6 cells. Plates were stained with neutral red two days after infection and plaques were counted $24 \mathrm{~h}$ after staining. Neutralization potency was calculated based on p.f.u. for each virus in the well without antibody. The experiments were performed in triplicate with independent virus preparations and duplicate readings for each replicate. Mean half-maximal inhibitory concentrations were calculated as previously described ${ }^{91}$.

Escape mutant analysis. Neutralization-resistant $\mathrm{NiV}$ mutants were generated by incubating $1 \times 10^{5} 50 \%$ tissue culture infective dose $\left(\mathrm{TCID}_{50}\right)$ of each virus with a sub-neutralizing concentration of $40 \mu \mathrm{g}$ of $5 \mathrm{~B} 3 \mathrm{IgG}$, in $100 \mu \mathrm{l}$ medium for $1 \mathrm{~h}$ at $37^{\circ} \mathrm{C}$ and then inoculated onto $1 \times 10^{6}$ VeroE6 cells in the presence of IgG at the same concentration. The development of cytopathic effects was monitored over $72 \mathrm{~h}$ and progeny viruses were harvested. IgG treatment was repeated two additional times, with cytopathic effects developing slowly with each passage. Viruses from the third passage were plaque purified in the presence of $\operatorname{IgG}$ and neutralization resistant viruses were isolated. The experiment was performed in duplicate and the F and G glycoprotein genes of five individual plaques were sequenced. The neutralization titers between wild type and the neutralizationresistant virus were determined using a micro-neutralization assay. Briefly, the $5 B 3$ IgG was serially diluted two fold and incubated with 100 TCID $_{50}$ of the wild-type and neutralization-resistant $\mathrm{NiV}$ for $1 \mathrm{~h}$ at $37^{\circ} \mathrm{C}$. Virus and antibodies were then added to a 96-well plate with $2 \times 10^{4}$ VeroE6 cells per well in four wells per antibody dilution. Wells were checked for cytopathic effects three days post infection and the mean half-maximal inhibitory concentrations was determined as the mAb concentration at which at least $50 \%$ of wells showed no cytopathic effects.

Reporting Summary. Further information on experimental design is available in the Nature Research Reporting Summary linked to this article.

\section{Data availability}

The sharpened and unsharpened cryo-EM maps and atomic model have been deposited in the EMDB and wwPDB with accession codes EMD-20584 and 6TYS, respectively. The 5B3 Fab crystal structure has been deposited in the wwPDB with accession code 6U1T. Uncropped images for Fig. 4d,e and Extended Data 4 are available online.

\section{References}

54. Debat, H. et al. Overpassing an aberrant Vк gene to sequence an antiidiotypic abzyme with $\beta$-lactamase-like activity that could have a linkage with autoimmune diseases. FASEB J. 15, 815-822 (2001).

55. Wang, Z. et al. Universal PCR amplification of mouse immunoglobulin gene variable regions: the design of degenerate primers and an assessment of the effect of DNA polymerase $3^{\prime}$ to $5^{\prime}$ exonuclease activity. J. Immunol. Methods 233, 167-177 (2000).

56. Zhu, Z. \& Dimitrov, D. S. Construction of a large naive human phagedisplayed Fab library through one-step cloning. Methods Mol. Biol. 525 , 129-142 (2009).

57. Dimitrova, D., Choudhry, V. \& Broder, C. C. Antibody fragment expression and purification. Methods Mol. Biol. 525, 491-498 (2009).

58. Chan, Y. P., Yan, L., Feng, Y. R. \& Broder, C. C. Preparation of recombinant viral glycoproteins for novel and therapeutic antibody discovery. Methods Mol. Biol. 525, 31-58 (2009).

59. Feng, Y. \& Dimitrov, D. S. Scaling-up and production of therapeutic antibodies for preclinical studies. Methods Mol. Biol. 525, 499-508 (2009).

60. Kabsch, W. XDS. Acta Crystallogr. D Biol. Crystallogr. 66, 125-132 (2010).

61. Evans, P. R. \& Murshudov, G. N. How good are my data and what is the resolution? Acta Crystallogr. D Biol. Crystallogr. 69, 1204-1214 (2013).

62. McCoy, A. J. et al. Phaser crystallographic software. J. Appl. Crystallogr. 40, 658-674 (2007).

63. Walls, A. C. et al. Unexpected receptor functional mimicry elucidates activation of coronavirus fusion. Cell 176, 1026-1039.e15 (2019).

64. Cowtan, K. The Buccaneer software for automated model building. 1. Tracing protein chains. Acta Crystallogr. D Biol. Crystallogr. 62, 1002-1011 (2006).
65. Emsley, P., Lohkamp, B., Scott, W. G. \& Cowtan, K. Features and development of Coot. Acta Crystallogr. D Biol. Crystallogr. 66, 486-501 (2010).

66. Blanc, E. et al. Refinement of severely incomplete structures with maximum likelihood in BUSTER-TNT. Acta Crystallogr. D Biol. Crystallogr. 60, 2210-2221 (2004).

67. Vagin, A. A. et al. REFMAC5 dictionary: organization of prior chemical knowledge and guidelines for its use. Acta Crystallogr. D Biol. Crystallogr. 60, 2184-2195 (2004).

68. Chen, V. B. et al. MolProbity: all-atom structure validation for macromolecular crystallography. Acta Crystallogr. D Biol. Crystallogr. 66, 12-21 (2010).

69. Suloway, C. et al. Automated molecular microscopy: the new Leginon system. J. Struct. Biol. 151, 41-60 (2005).

70. Zheng, S. Q. et al. MotionCor2: anisotropic correction of beam-induced motion for improved cryo-electron microscopy. Nat. Methods 14, 331-332 (2017).

71. Voss, N. R., Yoshioka, C. K., Radermacher, M., Potter, C. S. \& Carragher, B. DoG Picker and TiltPicker: software tools to facilitate particle selection in single particle electron microscopy. J. Struct. Biol. 166, 205-213 (2009).

72. Lander, G. C. et al. Appion: an integrated, database-driven pipeline to facilitate EM image processing. J. Struct. Biol. 166, 95-102 (2009).

73. Zhang, K. Gctf: real-time CTF determination and correction. J. Struct. Biol. 193, 1-12 (2016).

74. Zivanov, J. et al. New tools for automated high-resolution cryo-EM structure determination in RELION-3. Elife 7, e42166 (2018).

75. Punjani, A., Rubinstein, J. L., Fleet, D. J. \& Brubaker, M. A. cryoSPARC: algorithms for rapid unsupervised cryo-EM structure determination. Nat. Methods 14, 290-296 (2017).

76. Zivanov, J., Nakane, T. \& Scheres, S. H. W. A Bayesian approach to beam-induced motion correction in cryo-EM single-particle analysis. IUCrJ 6, 5-17 (2019)

77. Scheres, S. H. \& Chen, S. Prevention of overfitting in cryo-EM structure determination. Nat. Methods 9, 853-854 (2012).

78. Rosenthal, P. B. \& Henderson, R. Optimal determination of particle orientation, absolute hand and contrast loss in single-particle electron cryomicroscopy. J. Mol. Biol. 333, 721-745 (2003).

79. Chen, S. et al. High-resolution noise substitution to measure overfitting and validate resolution in $3 \mathrm{D}$ structure determination by single particle electron cryomicroscopy. Ultramicroscopy 135, 24-35 (2013).

80. Goddard, T. D., Huang, C. C. \& Ferrin, T. E. Visualizing density maps with UCSF Chimera. J. Struct. Biol. 157, 281-287 (2007).

81. Brown, A. et al. Tools for macromolecular model building and refinement into electron cryo-microscopy reconstructions. Acta Crystallogr. D Biol. Crystallogr. 71, 136-153 (2015).

82. DiMaio, F., Leaver-Fay, A., Bradley, P., Baker, D. \& Andre, I. Modeling symmetric macromolecular structures in Rosetta3. PLoS One 6, e20450 (2011)

83. DiMaio, F. et al. Atomic-accuracy models from 4.5 - $\AA$ cryo-electron microscopy data with density-guided iterative local refinement. Nat. Methods 12, 361-365 (2015).

84. Wang, R. Y. et al. Automated structure refinement of macromolecular assemblies from cryo-EM maps using Rosetta. Elife 5, e17219 (2016).

85. Frenz, B. et al. Automatically fixing errors in glycoprotein structures with Rosetta. Structure 27, 134-139 (2019).

86. Barad, B. A. et al. EMRinger: side chain-directed model and map validation for 3D cryo-electron microscopy. Nat. Methods 12, 943-946 (2015).

87. Agirre, J. et al. Privateer: software for the conformational validation of carbohydrate structures. Nat. Struct. Mol. Biol. 22, 833-834 (2015).

88. Goddard, T. D. et al. UCSF ChimeraX: meeting modern challenges in visualization and analysis. Protein Sci. 27, 14-25 (2018).

89. Bossart, K. N. \& Broder, C. C. Viral glycoprotein-mediated cell fusion assays using vaccinia virus vectors. Methods Mol. Biol. 269, 309-332 (2004).

90. Broder, C. C. et al. Antigenic implications of human immunodeficiency virus type 1 envelope quaternary structure: oligomer-specific and -sensitive monoclonal antibodies. Proc. Natl Acad. Sci. USA 91, 11699-11703 (1994).

91. Ferrara, F. \& Temperton, N. Pseudotype neutralization assays: from laboratory bench to data analysis. Methods Protoc. 1, 8 (2018). 
a

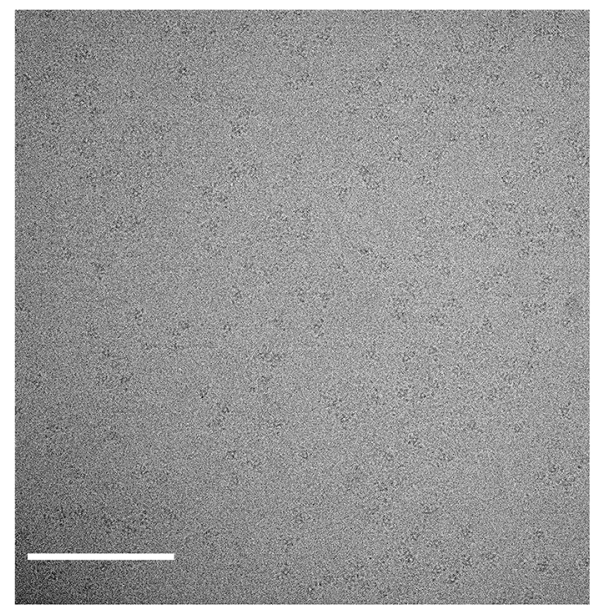

b

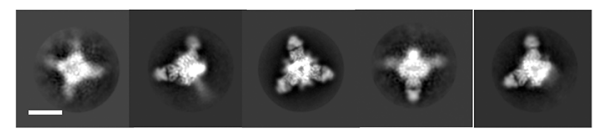

d

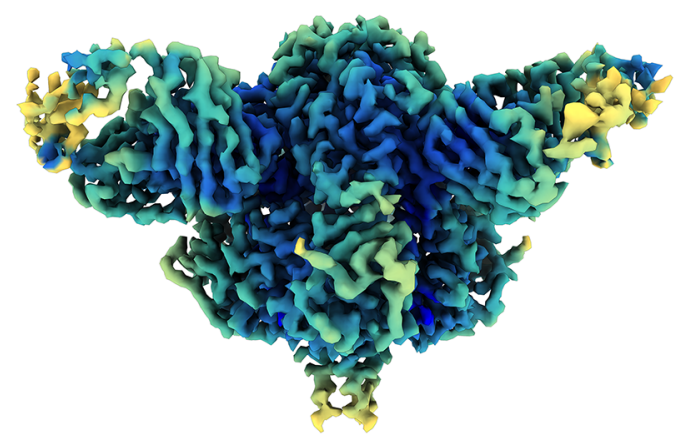

$\frac{\cap}{90^{\circ}}$

e

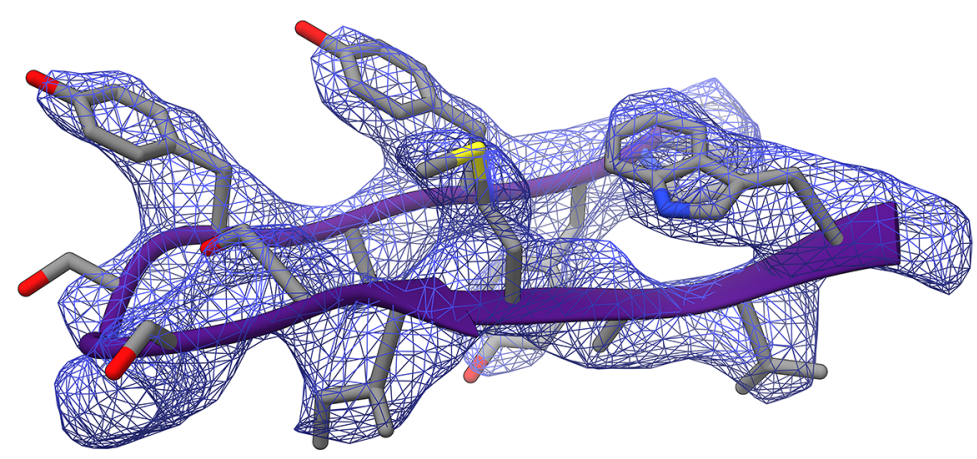

Viral membrane
C
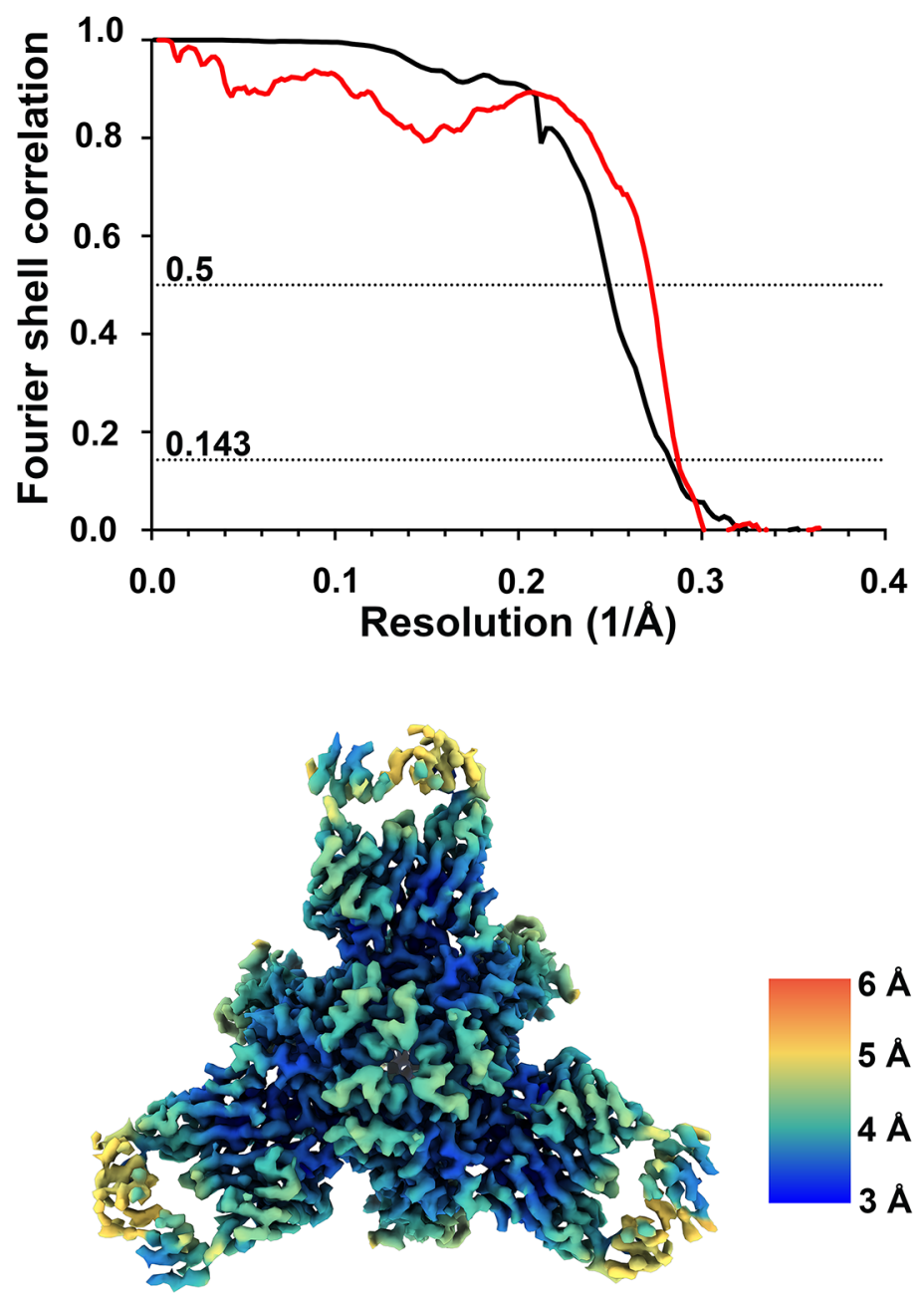

$6 \AA$

$5 \AA$

$4 \AA$

$3 \AA$

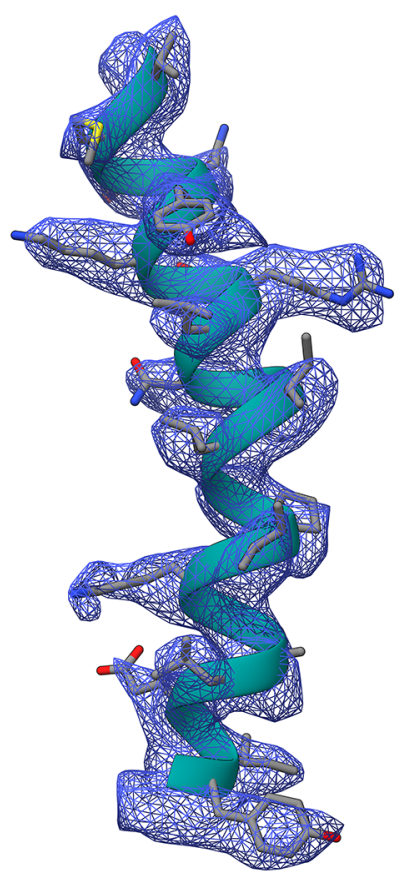

Extended Data Fig. 1 | Cryo-EM characterization of the NiV F glycoprotein in complex with the neutralizing antibody 5B3 Fab fragment.

a, Representative micrograph. Scale bar, $100 \mathrm{~nm}$. b, Reference-free 2D class averages. Scale bar, $100 \AA$. c, Gold-standard (black) and map/model (red) Fourier shell correlation curves. Dotted lines indicate 0.143 and 0.5 thresholds. $\mathbf{d}$, Two orthogonal views of the cryo-EM reconstruction colored by local resolution computed using cryoSPARC. e, Enlarged view of the model with the cryo-EM reconstruction rendered as a blue mesh. 
a

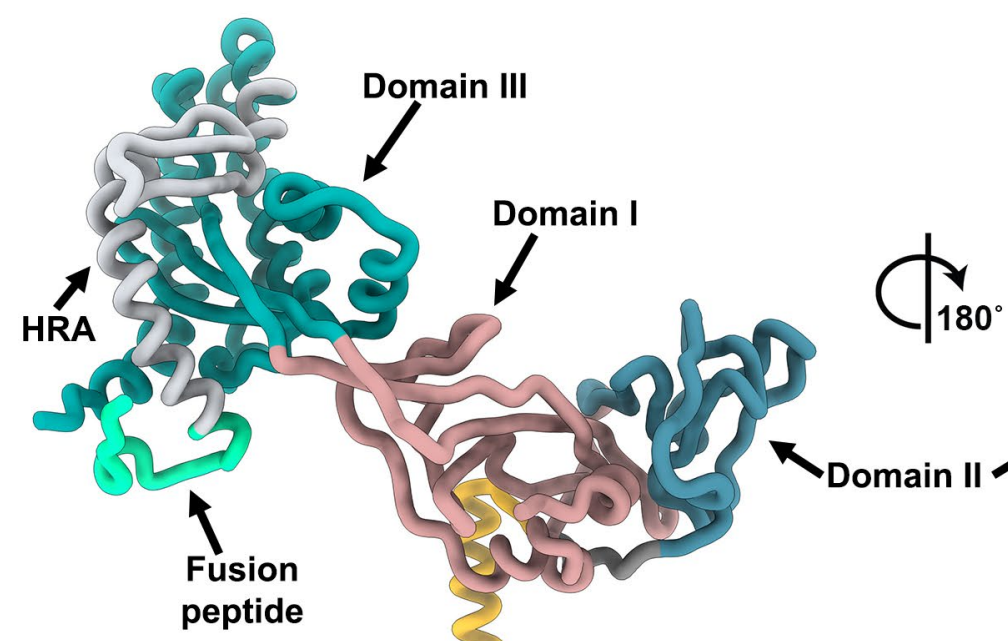

b

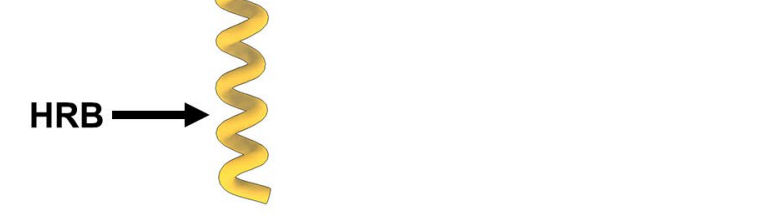

Extended Data Fig. 2 | Architecture of the prefusion NiV F glycoprotein. a,b, Ribbon diagrams of a NiV F ectodomain protomer from the cryo-EM structure of NiV F in complex with the 5B3 Fab fragment. HRA, heptad-repeat A; HRB, heptad-repeat B. 
a

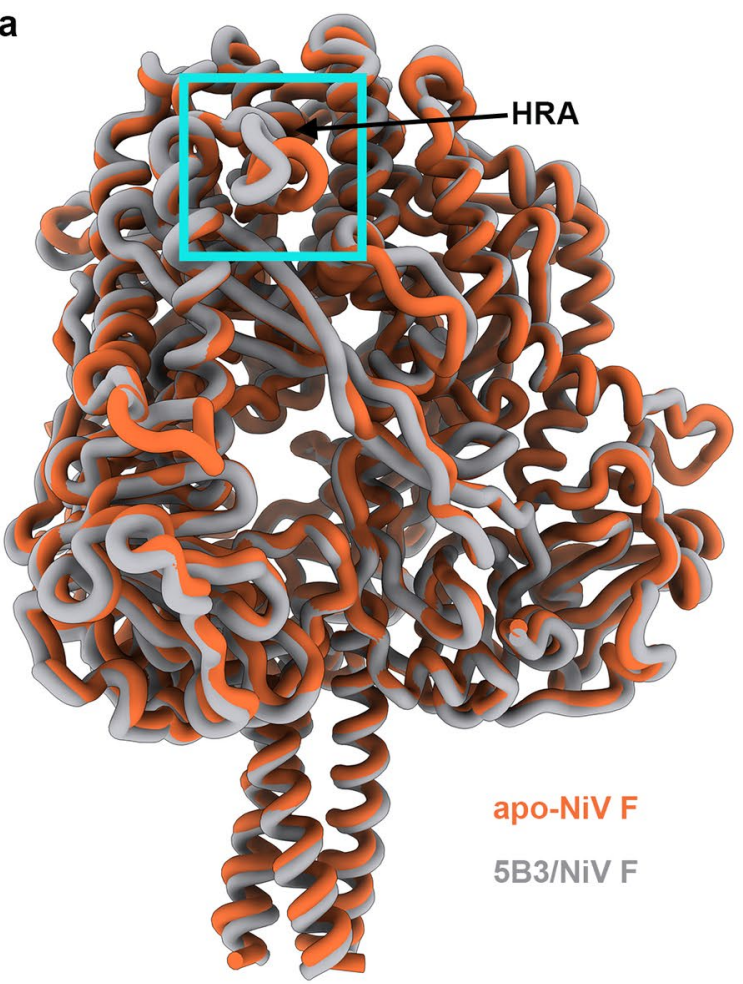

b

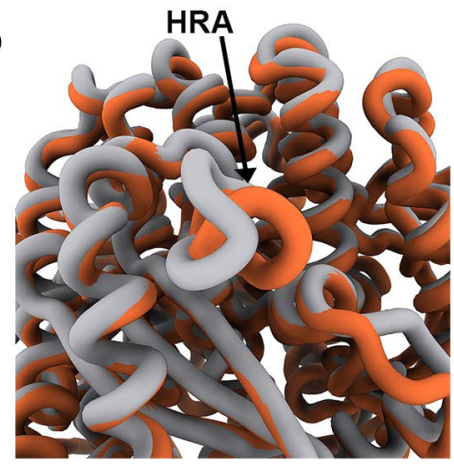

C

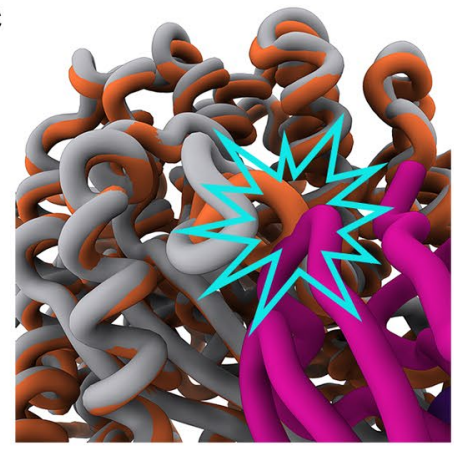

d

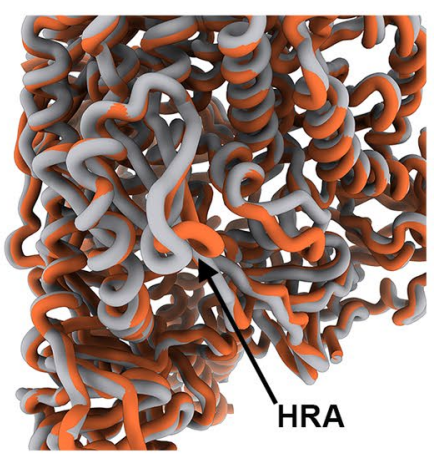

e

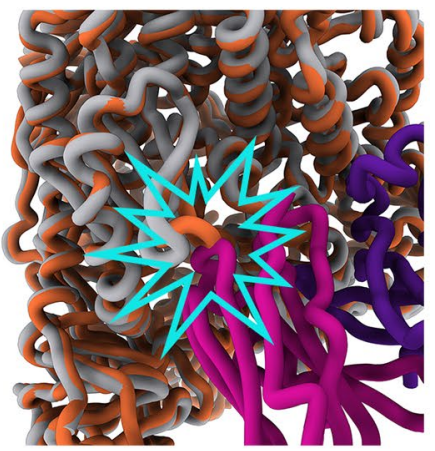

Extended Data Fig. 3 | 5 B3 binding is associated with a local structural reorganization of the HRA $\beta$-hairpin. a, Ribbon diagrams of the superimposed 5B3-bound and apo NiV F trimers. The 5B3 Fab fragments are omitted for clarity. The cyan square highlights the region of the structure shown in $\mathbf{b}$-e. $\mathbf{b}, \mathbf{c}$, Enlarged views showing the HRA conformational change. d,e, Enlarged views rotated $45^{\circ}$ relative to $\mathbf{b}$ and $\mathbf{c}$. In all panels, 5B3-bound and apo-NiV $\mathrm{F}$ trimers are rendered grey and orange, respectively. In c-e, one 5B3 Fab fragment is shown with its heavy and light chains colored purple and pink, respectively, whereas the cyan star indicates clashes that would occur between 5B3 and the HRA $\beta$-hairpin conformation observed in the apo-NiV structure $^{13}$ (PDB 5EVM). 
a

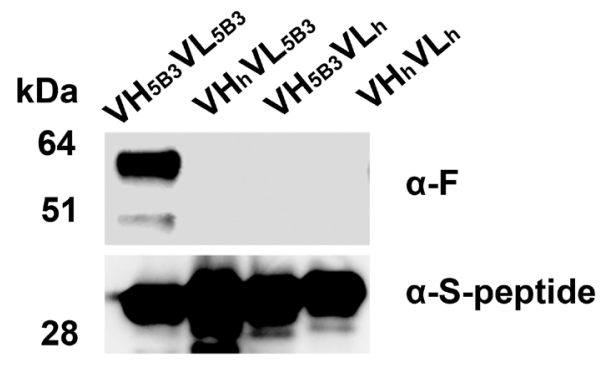

b

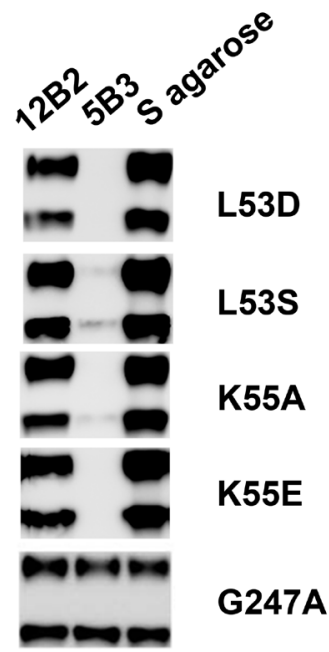

C

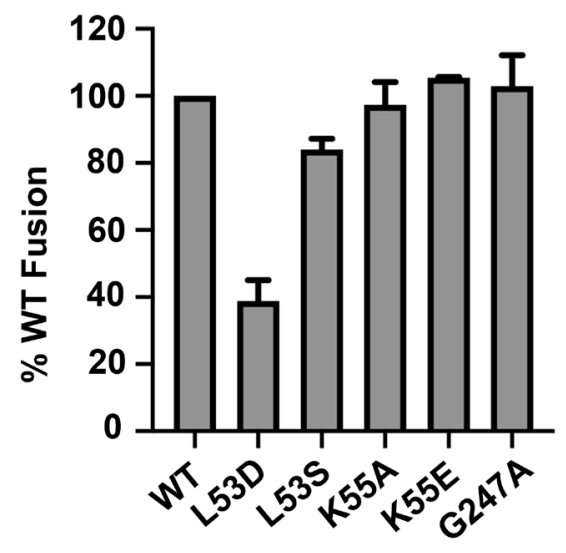

Extended Data Fig. 4 | Validation of the binding epitope on NiV F. a, Analysis of h5B3 scFv binding to full-length NiV F. scFv chimeric constructs in which the variable heavy $h 5 B 3$ chain $\left(V H_{5 B 3}\right)$, the variable light $h 5 B 3$ chain $\left(V L_{5 B 3}\right)$ or both chains were replaced with unrelated chains $\left(V H_{h} V L_{h}\right)$ from a human scFv library were assessed for binding to secreted wild-type NiV F. VH ${ }_{5 B 3} / \mathrm{VL}_{5 B 3}$ scFv was used as a positive control. Western blotting was carried out using an anti-F polyclonal antibody to detect NiV F or anti-S-peptide antibody to detect the scFv. b. Site-directed mutagenesis of the 5B3 epitope. A panel of S-peptide tagged NiV F ectdomain mutants were generated and expressed in HEK 293T cells. The F-expressing cell lysates were divided equally and incubated with 5B3, 12B2 or S-protein agarose before immunoprecipitation/pulldown. Samples in which mAb 5B3 or 12B2 were added were precipitated with protein G Sepharose. Western blotting detection of the precipitated products was carried out using an anti-S-peptide antibody. The Gly247Ala substitution was used as positive control. c, Cell-cell fusion mediated by the NiV F mutants shown in $\mathbf{b}$. Data are the mean percentage of wild-type fusion levels for each mutant normalized relative to total F expression, as measured by densitometry of western blot bands. The bars represent the standard error from three separate experiments. 


\section{Reporting Summary}

Nature Research wishes to improve the reproducibility of the work that we publish. This form provides structure for consistency and transparency in reporting. For further information on Nature Research policies, see Authors \& Referees and the Editorial Policy Checklist.

\section{Statistics}

For all statistical analyses, confirm that the following items are present in the figure legend, table legend, main text, or Methods section.

$\mathrm{n} / \mathrm{a}$ Confirmed

$\bigotimes$ The exact sample size $(n)$ for each experimental group/condition, given as a discrete number and unit of measurement

\ A statement on whether measurements were taken from distinct samples or whether the same sample was measured repeatedly

$\triangle \square$ The statistical test(s) used AND whether they are one- or two-sided

$\triangle \square$ Only common tests should be described solely by name; describe more complex techniques in the Methods section.

Х $\square$ A description of all covariates tested

Х $\square$ A description of any assumptions or corrections, such as tests of normality and adjustment for multiple comparisons

$\triangle$ A full description of the statistical parameters including central tendency (e.g. means) or other basic estimates (e.g. regression coefficient)

X AND variation (e.g. standard deviation) or associated estimates of uncertainty (e.g. confidence intervals)

$X$ For null hypothesis testing, the test statistic (e.g. $F, t, r$ ) with confidence intervals, effect sizes, degrees of freedom and $P$ value noted

$\triangle \square$ For null hypothesis testing, the test statistic

Х $\square$ For Bayesian analysis, information on the choice of priors and Markov chain Monte Carlo settings

Х $\square$ For hierarchical and complex designs, identification of the appropriate level for tests and full reporting of outcomes

Х $\square$ Estimates of effect sizes (e.g. Cohen's $d$, Pearson's $r$ ), indicating how they were calculated

\section{Our web collection on statistics for biologists contains articles on many of the points above.}

\section{Software and code}

\section{Policy information about availability of computer code}

\section{Data collection N/A}

Data analysis

$$
\text { N/A }
$$

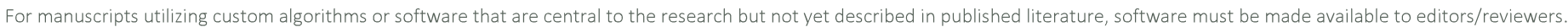
We strongly encourage code deposition in a community repository (e.g. GitHub). See the Nature Research guidelines for submitting code \& software for further information.

Policy information about availability of data

All manuscripts must include a data availability statement. This statement should provide the following information, where applicable:

- Accession codes, unique identifiers, or web links for publicly available datasets

- A list of figures that have associated raw data

- A description of any restrictions on data availability

The sharpened and unsharpened cryoEM map and atomic model have been deposited in the Electron Microscopy Data Bank and the Protein Data Bank with accession codes EMD-20584 and PDB 6TYS. The 5B3 Fab crystal structure has been deposited in the Protein Data Bank with accession code PDB 6U1T.

\section{Field-specific reporting}

Please select the one below that is the best fit for your research. If you are not sure, read the appropriate sections before making your selection. 


\section{Life sciences study design}

All studies must disclose on these points even when the disclosure is negative.

$\begin{array}{ll}\text { Sample size N/A } & \text { Nata exclusions N/A } \\ \text { Replication N/A } & \text { N/A } \\ \text { Randomization } & \\ \text { Reporting for specific materials, systems and methods }\end{array}$

We require information from authors about some types of materials, experimental systems and methods used in many studies. Here, indicate whether each material, system or method listed is relevant to your study. If you are not sure if a list item applies to your research, read the appropriate section before selecting a response.

\begin{tabular}{|c|c|c|c|}
\hline \multicolumn{2}{|r|}{ Materials \& experimental systems } & \multicolumn{2}{|c|}{ Methods } \\
\hline $\mathrm{n} / \mathrm{a}$ & Involved in the study & $n / a$ & Involved in the study \\
\hline - & $\bigotimes$ Antibodies & $\bigotimes$ & $\square$ ChIP-seq \\
\hline \begin{tabular}{|r} 
\\
\end{tabular} & $\bigotimes$ Eukaryotic cell lines & $\bigotimes$ & $\square$ Flow cytometry \\
\hline Х & $\square$ Palaeontology & Х & $\square$ MRI-based neuroimaging \\
\hline Х & $\square$ Animals and other organisms & & \\
\hline Х & $\square$ Human research participants & & \\
\hline Х & $\square$ Clinical data & & \\
\hline
\end{tabular}

\section{Antibodies}

Antibodies used

Validation
Rabbit anti-NiV-F polyclonal antibody (Spring Valley Laboratories, Inc.), HRP-conjugated rabbit anti-S-peptide antibody (Bethyl Laboratories, Inc.)

None

\section{Eukaryotic cell lines}

Policy information about cell lines

Cell line source(s)

Authentication

Mycoplasma contamination

Commonly misidentified lines (See ICLAC register)
Life technologies HEK293F, ATCC HEK293T, USU-HELA

HeLa-USU cells, ephrin-B2 and ephrin-B3 negative, (kind gift from Anthony Maurelli, Uniformed Services University and HeLaCCL2, ephrin-B2 positive (ATCC) have previously undergone cytogenetic analysis. Other cell lines were not authenticated.

\section{Cell lines were not tested for mycoplasma contamination.}

N/A 